\title{
A 10-Year Warm-Season Climatology of Horizontal Convective Rolls and Cellular Convection in Central Oklahoma
}

\author{
John R. BAnghoff, Jacob D. Sorber, David J. Stensrud, George S. Young, And \\ MATTHEW R. KUMJIAN \\ Department of Meteorology and Atmospheric Science, The Pennsylvania State University, University Park, Pennsylvania
}

(Manuscript received 2 May 2019, in final form 24 September 2019)

\begin{abstract}
Horizontal convective rolls (HCRs) and cellular convection (cells) are frequently observed within the planetary boundary layer. Yet understanding of the evolution, seasonal variation, and characteristics of such boundary layer phenomena is limited as previous studies used observations from field experiments or satellites. As a result, little is known about the mean climatology and monthly variation of HCRs and cells. Polarimetric WSR-88D radar observations are used to develop a 10-yr April-September climatology in central Oklahoma including HCR and cell occurrence, duration, and aspect ratios as well as HCR orientation angles and wavelengths. Results indicate that HCRs or cells occur on over $92 \%$ of days without precipitation during the warm season. HCRs or cells typically form in midmorning and may persist throughout the day or transition between modes before dissipating around sunset. HCRs generally persist for 1-6h with typical wavelengths of $2-10 \mathrm{~km}$ and most aspect ratios between 1 and 7 . Rolls are often oriented within $10^{\circ}$ of the mean boundary layer wind but can be as much as $30^{\circ}$ off this direction. Mean HCR aspect ratios in this study remain constant during the afternoon, but decrease early in the day and increase late in the day, diverging from previous overland HCR studies. Cells generally persist for $2-6 \mathrm{~h}$ with aspect ratios of $1-6$. These results should facilitate future studies on convection initiation, formation mechanisms of boundary layer organization, and model parameterization.
\end{abstract}

\section{Introduction}

Horizontal convective rolls (hereafter HCRs or rolls) are common occurrences in the planetary boundary layer and influence boundary layer circulations, boundary layer structure, and initiation of deep convection. Numerous studies have investigated HCR behavior and documented typical HCR characteristics (Schuetz and Fritz 1961; Angell et al. 1968; Kuettner 1971; LeMone 1973; Berger and Doviak 1978; Reinking et al. 1981; Atkinson and Zhang 1996; Young et al. 2002), but a multiyear HCR climatology has yet to be compiled. The first observation of HCR circulations relied on viewing the flight patterns of soaring birds. When winds were weak, gulls would rise in a corkscrew pattern. When winds increased, however, birds would rise and soar along straight flight tracks (Woodcock 1942). Based on this observation, Woodcock identified the elongated updraft regions that would later come to

Corresponding author: John R. Banghoff, john.banghoff@ noaa.gov be associated with HCRs. Identification of this phenomenon became very useful for glider pilots in the midtwentieth century (Kuettner 1959). The AMS Glossary defines HCRs as "counter-rotating horizontal vortices that commonly occur within the convective boundary layer" (American Meteorological Society 2019). Along the updraft portion of HCRs, rising air cools, sometimes resulting in cloud formation. These parallel lines of clouds are seen in visible satellite images and are called cloud streets (Kuettner 1959). Plank (1966) studied cloud photos from high-flying aircraft and was one of the first to systematically characterize cloud streets and investigate environmental conditions favorable for such organization. Cloud streets are particularly observable in the winter over oceans when cold continental air moves over the warmer ocean, and rising thermals are organized by the prevailing offshore winds into HCRs (Atlas et al. 1983, 1986). As their distance from the shoreline increases, HCRs often transition into cellular convection (Rothermel and Agee 1980; Bakan and Schwarz 1992; Atkinson and Zhang 1996; Kristovich et al. 1999). 
Past studies document a number of HCR characteristics and note that HCR evolution may be related to boundary layer depth (Fankhauser et al. 1995). HCRs often form with sufficiently strong winds or wind shear $\left(1-10 \mathrm{~m} \mathrm{~s}^{-1} \mathrm{~km}^{-1}\right)$ in an unstable boundary layer, which is present when the surface is warmer than the air flowing over it (Atkinson and Zhang 1996). Such conditions favorable for roll formation frequently occur over land in the warm season or over large lakes and oceans in the winter. Although all HCRs exhibit certain similarities independent of the environment in which they form, there are some important differences. Rolls that form over land are called narrow mode rolls (Atkinson and Zhang 1996) because they are characterized by smaller aspect ratios, defined as the ratio of wavelength to boundary layer depth, where wavelength is defined as the spacing between updraft regions (Young et al. 2002). Narrow mode rolls tend to form in neutral or weakly unstable boundary layers, and have aspect ratios of 1-4 that are approximately constant with boundary layer depth (Atkinson and Zhang 1996). In contrast, rolls that form over oceans or large lakes in the cold season tend to have much larger aspect ratios. Socalled wide mode rolls can have wavelengths of up to $30 \mathrm{~km}$ and aspect ratios of 10-20 (Atkinson and Zhang 1996). Wide rolls exhibit aspect ratios that increase with boundary layer depth (Young et al. 2002). Another frequently investigated HCR characteristic is roll orientation. Expressed as a departure from the mean boundary layer wind or wind shear vector, roll orientation tends to fall within $30^{\circ}$ of the mean wind direction but most often is observed to occur within $10^{\circ}$ (Etling and Brown 1993; Atkinson and Zhang 1996; Weckwerth et al. 1999).

Cellular convection differs from HCRs in that the updraft/downdraft pattern is circular or hexagonal in the horizontal instead of linear (Agee et al. 1973; Agee and Dowell 1974; Bennett et al. 2010). Satellite observations have been a key component in many studies of cellular convection, because cells are most frequent over ocean waters to the east of the continents (Agee et al. 1973; Agee and Dowell 1974; Atkinson and Zhang 1996); however, cells are also observed using radar over land (Hardy and Ottersten 1969; Konrad 1970; Weckwerth et al. 1999; Bennett et al. 2010). Cells are typically observed within deeper boundary layers than rolls (Brümmer 1999), and often are associated with weaker wind shear (Atkinson and Zhang 1996) or weaker wind speeds (Weckwerth et al. 1999). Cells over land typically have aspect ratios between 1 and 5 (Hardy and Ottersten 1969; Konrad 1970), where aspect ratios near one are likely associated with thermals rising in the boundary layer (Hardy and Ottersten 1969) and larger values of aspect ratio are associated with Rayleigh instability
(Agee and Dowell 1974). Transitions between HCRs and cells also are observed (Braham 1986; Weckwerth et al. 1999; Kristovich et al. 1999; Miles and Verlinde 2005a,b), although how frequently this occurs is unknown. Weckwerth et al. (1999) suggest that as the convective boundary layer becomes more convectively unstable, HCRs are replaced by cells.

Though both satellites and radar have been used to study HCRs and cells, the most robust way to identify boundary layer circulations is through the use of radar because of a radar's ability to detect boundary layer circulations even when clouds are not present. Several studies have identified HCRs or cells using radar observations (Angell et al. 1968; Berger and Doviak 1978; Hildebrand 1980; Reinking et al. 1981; Kelly 1982; Christian and Wakimoto 1989; Russell and Wilson 1997; Weckwerth et al. 1997; Yang and Geerts 2006). Christian and Wakimoto (1989), Hardy and Ottersten (1969), and Konrad (1970) explore the linear and hexagonal features seen in equivalent radar reflectivity factor, hereafter "reflectivity," associated with cloud streets and cells. Updraft regions produce enhanced reflectivity as a result of an increased concentration of biota as insects actively resist upward vertical motion (Wilson et al. 1994; Geerts and Miao 2005). In downdraft regions of these circulations, the concentration of insects and other biota is smaller, so reflectivity is reduced. Thus, whenever HCRs or cells are present, if there are sufficient biota in the atmosphere, a clear $\mathrm{HCR} /$ cell signature of parallel/hexagonal higher-reflectivity features is observable. In the winter, HCRs can form lake-effect snowbands; in this case, the radar detects snowflakes along HCR updrafts.

Many of the techniques that utilize radar data to characterize rolls have been developed using HCR cases over the Great Lakes in winter. Subtle differences exist between HCRs over land and over water, as discussed earlier and in Atkinson and Zhang (1996), but the radar signatures associated with HCRs in both scenarios are comparable. As such, the radar-based techniques used to investigate lake-effect HCR bands over the Great Lakes can be applied to overland HCR cases.

A majority of our understanding of HCR and cell evolution and characteristics has come from observational and modeling case studies consisting of a few to tens of cases. Large eddy simulations have produced roll-like circulations since Deardorff (1972) and highresolution convection allowing models now produce HCR-type features; however, these model-generated HCRs and cells are only partially represented and may be caused by erroneous parameterizations of and circulations within the planetary boundary layer (Ching et al. 2014). In addition, a change in model resolution 

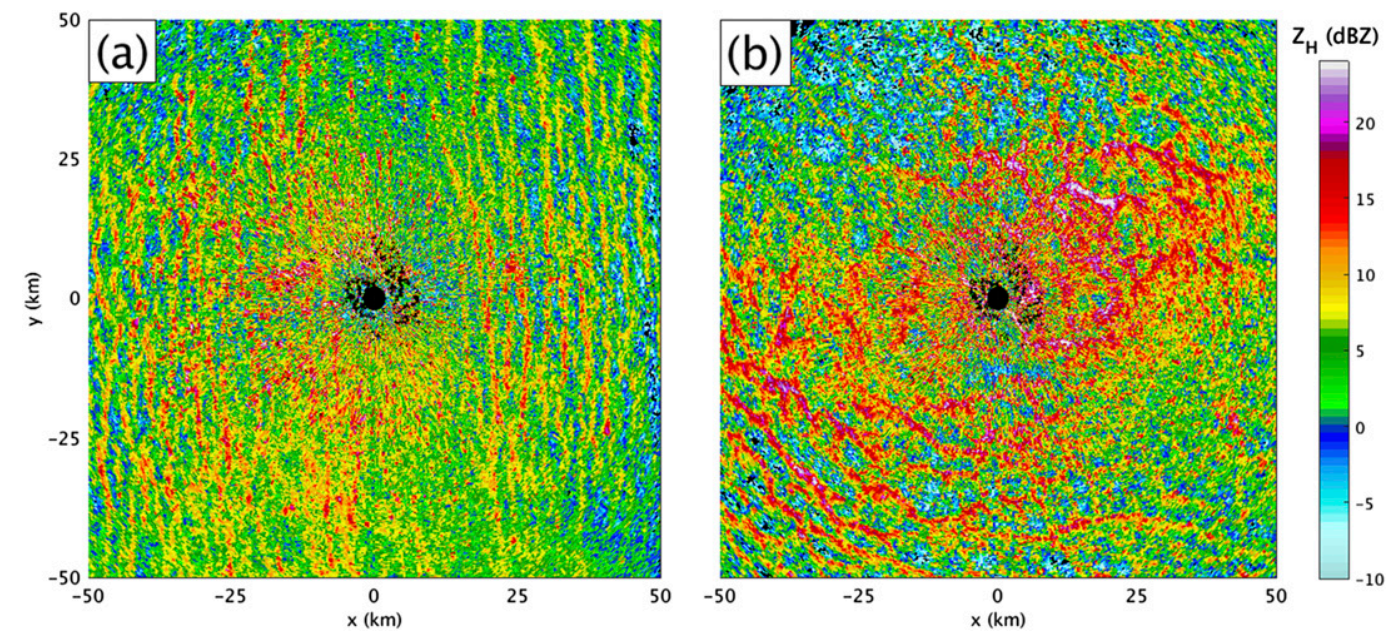

FIG. 1. Equivalent radar reflectivity factor $Z_{H}$ at $1.4^{\circ}$ (a) at 2142 UTC 16 Jun 2014 at KTLX, showing a classic HCR signature with clearly defined linear echoes, and (b) at 1836 UTC 29 Sep 2014 at KTLX, showing a classic cellular convection signature with clearly defined circular echoes. Such echoes occur as the radar scans insects lofted in updrafts associated with HCRs. The associated absence of echoes represent locations of downdrafts where insects are vertically suppressed.

can make HCRs disappear, so they are not robust (LeMone et al. 2010). An expanded exploration of HCR- and cell-type characteristics (frequency, spatial scale, orientation, and distribution) is needed to better understand HCR and cell occurrence and improve evaluation of model-generated HCR-like features. Additionally, HCRs have been identified as an important factor in initiation of deep convection (Christian and Wakimoto 1989; Wilson et al. 1992; Fankhauser et al. 1995; Weckwerth et al. 2008; Wakimoto and Wilson 1989), primarily when interacting with boundaries such as drylines, airmass fronts, and sea breezes.

The intent of this research is to develop a larger database of HCR and cell characteristics that can be used to investigate a variety of outstanding questions related to HCR and cell formation mechanisms, processes leading to convection initiation, and the accuracy of boundary layer parameterization schemes. To accomplish this goal, the present study characterizes HCR and cell structures and behaviors during the months of April through September over a 10 -yr period from 2008 to 2017 using observations from the Twin Lakes, Oklahoma, WSR-88D (KTLX). This study will provide valuable information with a scope that far exceeds any previous HCR or cell observational study. Central Oklahoma is the location of choice because of the prevalence of insects during the warm season, when the mean monthly temperatures are above $16^{\circ} \mathrm{C}$. Additionally, the flat terrain minimizes interference with boundary layer circulations and, when combined with the absence of significant beam blockage, results in simpler observations of boundary layer circulations.
Frequent clear-air scanning provided by the KTLX radar, with full volume scans completed every $10 \mathrm{~min}$, allows one to investigate the daytime evolution of HCRs and cells. The 10 years investigated in this study reflect the most recent set of complete yearly radar data from the KTLX radar in central Oklahoma, which allows for maximum use of dual-polarization radar data for analysis.

Section 2 describes the methods employed to develop a warm-season HCR and cell climatology of boundary layer circulations using radar observations. Results from the climatology in section 3 preface a summary of results and suggestions for future research in section 4 .

\section{Methods for detection of boundary layer circulations}

A low-level plan position indicator (PPI) display of reflectivity from KTLX on 16 June 2014 shows parallel linear regions of enhanced reflectivity indicative of HCRs in the boundary layer (Fig. 1a). Reflectivity values within the HCR updrafts in Fig. 1 are in the 5-20 dB $Z$ range, consistent with previous studies (e.g., Christian and Wakimoto 1989). Other types of boundary layer circulations are also observable with radar during the warm season. For example, cellular convection is observed on 29 September 2014, as indicated by roughly circular regions of enhanced reflectivity (Fig. 1b). These PPIs demonstrate the relative ease of visually differentiating echoes associated with HCRs from other types of circulations owing to the linear structure of parallel bands. Herein, we define "boundary layer organization" 
as being when HCRs and/or cellular convection are present as inferred from radar imagery. This focus upon radar observations for detection means that clouds may or may not be present in association with the boundary layer circulations, which could influence the HCR and cellular convection statistics (LeMone and Pennell 1976; Sheu et al. 1980; Helfand and Kalnay 1983; Sykes et al. 1988; Laufersweiler and Shirer 1989; Chlond 1992). In contrast, when there is widespread precipitation or no clear reflectivity pattern, we consider this a lack of boundary layer organization. This characterization will be referenced throughout this manuscript and is a vital building block for the methods outlined next.

Our methods can be separated into the following steps: (i) identifying boundary layer organization, (ii) differentiating HCRs from cellular convection, and (iii) investigating HCR and cell characteristics. These methods were developed using the 2014 dataset and are applied uniformly to all other years to complete the climatology.

\section{a. Identifying boundary layer organization}

The visual appearance of radar reflectivity PPI displays on days with boundary layer organization (defined as times when cellular convection and/or HCRs are present) is distinctly different from days with no organization or with precipitation. A number of methods were evaluated to automate the identification of boundary layer organization using either reflectivity or radial velocity observations, including spatial autocorrelation (Weckwerth et al. 1997) and harmonic analysis (Bloomfield 2004). The use of autocorrelation and harmonic analysis sought to leverage the periodic behavior of reflectivity for a given radial radar scan. For HCRs, the dominant wavelength of radial reflectivity should maximize for a radial perpendicular to roll orientation and minimize for a radial parallel to roll orientation. For cells, however, there would be very little azimuthal variability in wavelength. Unfortunately, hybrid HCR/cell cases and heterogeneous signatures across the domain result in inconsistent success using autocorrelation and harmonic analysis, so both methods were abandoned.

The method found to be most successful at identifying candidate days with boundary layer organization is based on the velocity-azimuth display (VAD) (Browning and Wexler 1968). The VAD method can be used to estimate wind speed and direction from radial wind observations at a fixed range from the radar. Kelly (1982) uses the VAD technique to identify perturbations in the velocity field associated with circulations of HCRs over Lake Michigan. He finds that HCR circulations produce perturbations in a uniform horizontal wind field, which result in deviations from the VAD best-fit curve. Kelly (1982) quantifies the perturbations by computing residual radial velocity at all radials (radar-observed radial velocities minus VAD best-fit line). This VAD residual radial velocity calculation is effective for quantifying wind perturbations in a single volume scan. To investigate boundary layer winds over time, we compute the variance of residual radial velocities $\left(\sigma^{2}\right)$ for each volume scan and produce a time series. Larger residual radial velocity variance, hereafter RRVV, implies larger perturbations in the wind field. Based on Kelly (1982), one might expect RRVV to be higher when boundary layer organization is present owing to wind perturbations associated with HCRs or cellular convection.

To determine the RRVV characteristics of HCRs and cellular convection, it is helpful to investigate VADs for several different features: HCRs, a clear day with disorganized boundary layer convection (null case), and multicell thunderstorms (Fig. 2). The black line in each VAD (right column) is the sinusoidal fit to the radial velocity observations from radar (blue dots) as a function of azimuth; a purely sinusoidal variation in azimuth represents a perfectly uniform wind field across the radar domain. For the HCR case (Figs. 2a-c), the wind field closely follows the idealized best-fit sine curve with small deviations occurring at azimuths close to the direction of the mean wind field. In the null case (Figs. 2d$\mathrm{f}$ ), the wind field closely resembles uniform flow and has a slightly larger variance than the HCR case. The third case of multicell deep convection (Figs. 2g-i), however, shows that thunderstorm winds cause significant departures from the sinusoidal best-fit line, resulting in rather large residual radial velocities and large $\sigma^{2}$. As a result, $\sigma^{2}$ values remain large throughout the duration of multicell convection. These results imply that radial velocity departures from a sinusoidal best fit are larger when deep convection is ongoing. Although HCRs and cells perturb the wind field, the associated perturbations are much smaller than those caused by deep convection. Inspection of a much wider range of radar signatures and VAD-derived winds in this study corroborates the finding that RRVVs from VAD winds are smaller in the absence of deep convection. In summary, the RRVV is useful for separating boundary layer organization cases (HCRs and/or cells) and null cases (no or disorganized boundary layer convection) from deep convection cases. Manual inspection is needed to differentiate boundary layer organization from null cases.

An example of the reduction in RRVV owing to boundary layer organization is shown in Fig. 3. VAD winds and RRVV are computed using the $0.5^{\circ}$ elevation scan for ranges of $10,20,30$, and $40 \mathrm{~km}$ from the radar to span the depth of the boundary layer (these ranges 

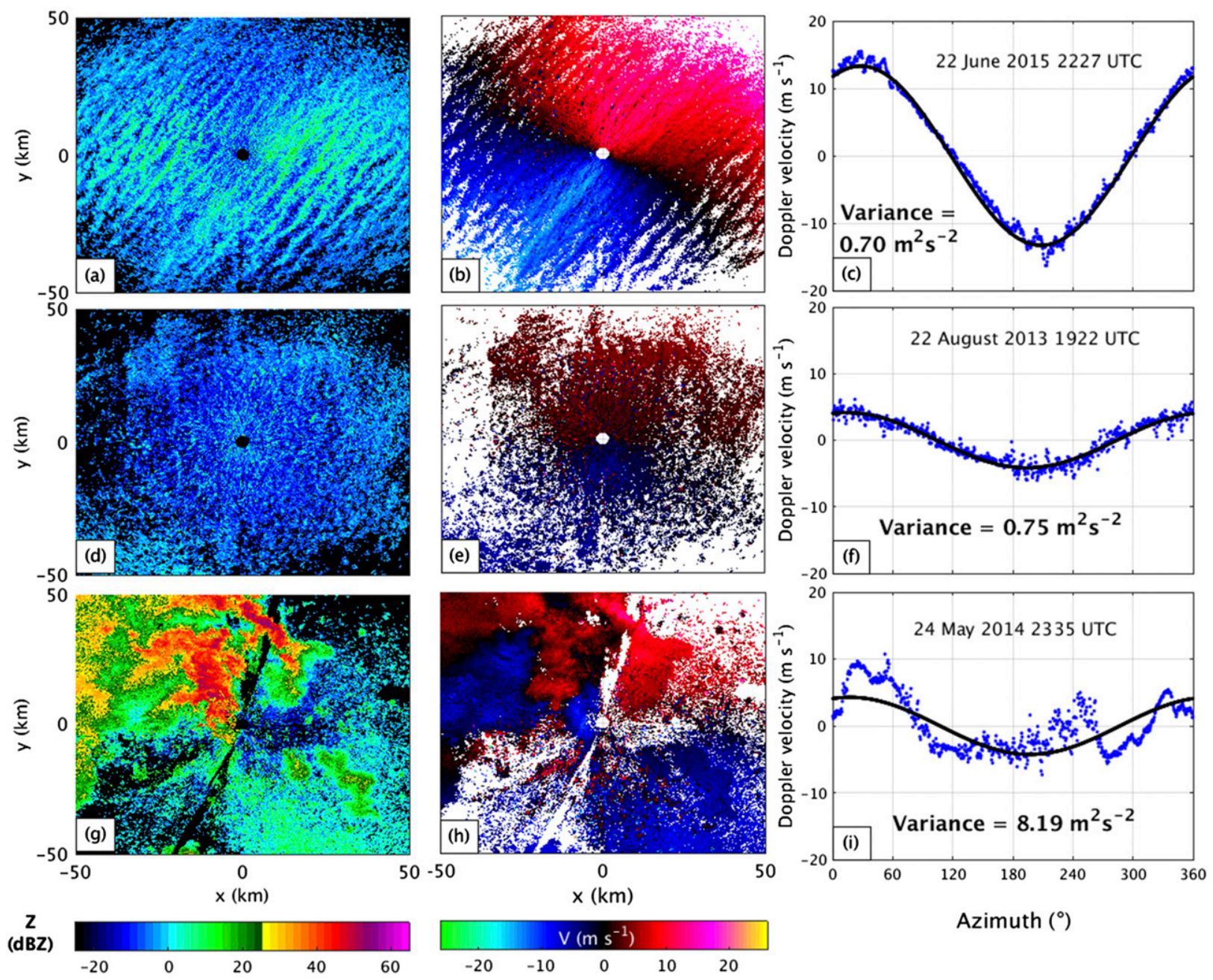

Azimuth $\left({ }^{\circ}\right)$

FIG. 2. $0.5^{\circ} Z_{H}(\mathrm{dBZ}), 0.5^{\circ} V\left(\mathrm{~m} \mathrm{~s}^{-1}\right)$, and velocity-azimuth display (VAD) computed between 35 and $45 \mathrm{~km}$ from KTLX during (a)-(c) HCRs on 22 Jun 2016, (d)-(f) a null case on 22 Aug 2013, and (g)-(i) multicell thunderstorms on 24 May 2014. The variance $\left(\sigma^{2}\right)$ of residual radial velocity (observed winds minus VAD-estimated winds) is listed on each VAD plot. Notice the residual radial velocity variance (RRVV) is largest for the thunderstorm case and below $1 \mathrm{~m}^{2} \mathrm{~s}^{-2}$ for the HCR and null cases. Lower variance implies increased uniformity of boundary layer winds and allows for filtering of days with deep convective activity.

correspond to beam heights of $0.27,0.53,0.80$, and $1.08 \mathrm{~km})$. RRVV is calculated over all azimuth angles for each radar scan between 1200 and 0000 UTC. Boundary layer organization may be present when the variances from each range segment are similar. Similarity is determined by calculating the variance of the four RRVVs at each time increment. The threshold for boundary layer organization is when the variance among the four time series is less than $1 \mathrm{~m}^{4} \mathrm{~s}^{-4}$. The authors thoroughly investigated the performance of the RRVV technique to identify convective boundary layer activity for all of 2014 and determined the threshold of 1 to be a reasonable discriminator. In this example, boundary layer organization is suggested from 1400 UTC to shortly after 2000 UTC. Comparison against the manual identification of boundary layer organization from reflectivity
PPI displays (black line) shows that the RRVV method over predicts the duration of boundary layer organization.

The RRVV method is verified against all manually identified boundary layer organization events in 2014 (Fig. 4). VAD RRVV-defined start and end times are compared with manually identified start and end times to compute the difference between them. Out of the 179 days in the warm season in 2014, 143 days are identified as having boundary layer organization. The RRVV method correctly identifies 140 days with boundary layer organization, with only 3 days on which boundary layer organization was observed but not diagnosed. Additionally, the mean and median departures for start and end time indicate that the method diagnoses boundary layer organization $\sim 2.5 \mathrm{~h}$ earlier than 


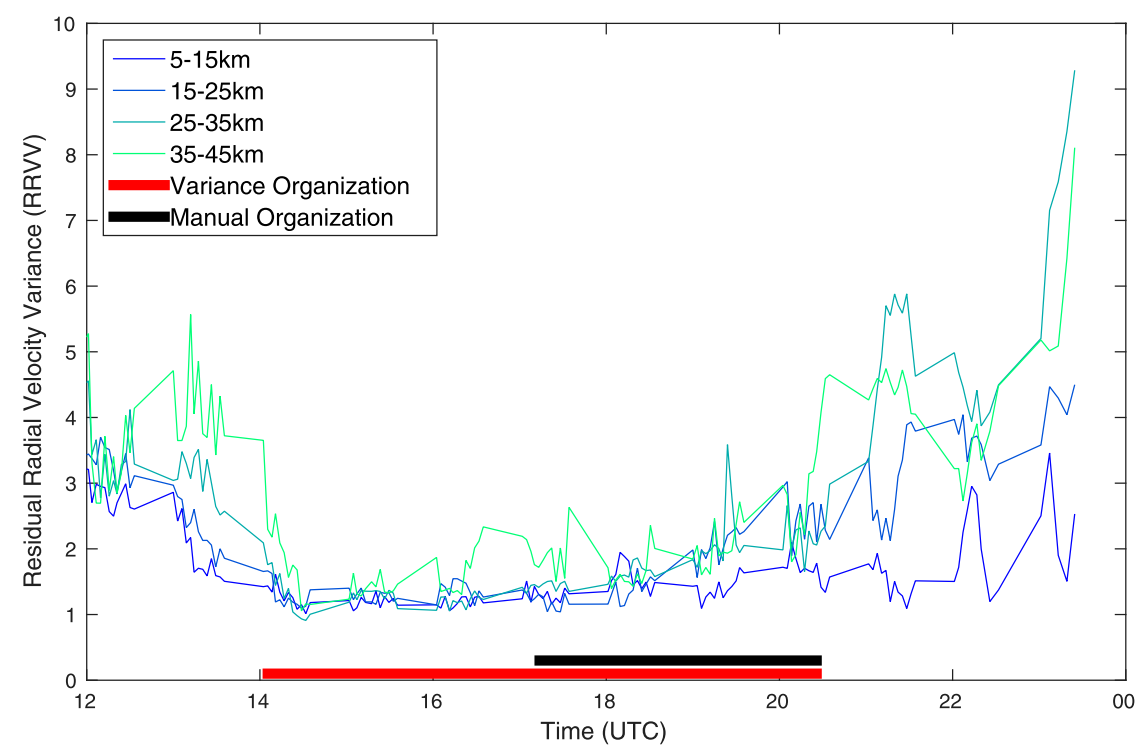

FIG. 3. Time series of residual radial velocity variances (RRVVs, $\mathrm{m}^{2} \mathrm{~s}^{-2}$ ) from VAD analysis for $29 \mathrm{Jul} 2014$ at KTLX. Velocity-azimuth displays and RRVVs are calculated for range rings of 5-15, 15-25, 25-35, and 35-45 km distance from the radar (centered on beam heights of $0.27,0.53,0.80$, and $1.08 \mathrm{~km}$, respectively). The red bar indicates the algorithmidentified time range of boundary layer organization. Boundary layer organization is defined when the variance among the 4 VAD RRVVs drops below $1 \mathrm{~m}^{4} \mathrm{~s}^{-4}$ implying a convergence of the various time series. The black bar indicates the duration of manually identified boundary layer organization.

observed and maintains boundary layer organization $\sim 30$ min after it dissipates (Fig. 4). As an aside, this indicates there may be some skill in using this technique to predict the onset of boundary layer convection (whether organized or not). With the aforementioned evaluation in mind, this method is then used to identify days on which boundary layer organization may be present for all 10 years of the climatology. This method significantly reduces the time and effort spent on manual analysis by filtering $\sim 20 \%$ of the cases (those with precipitation as
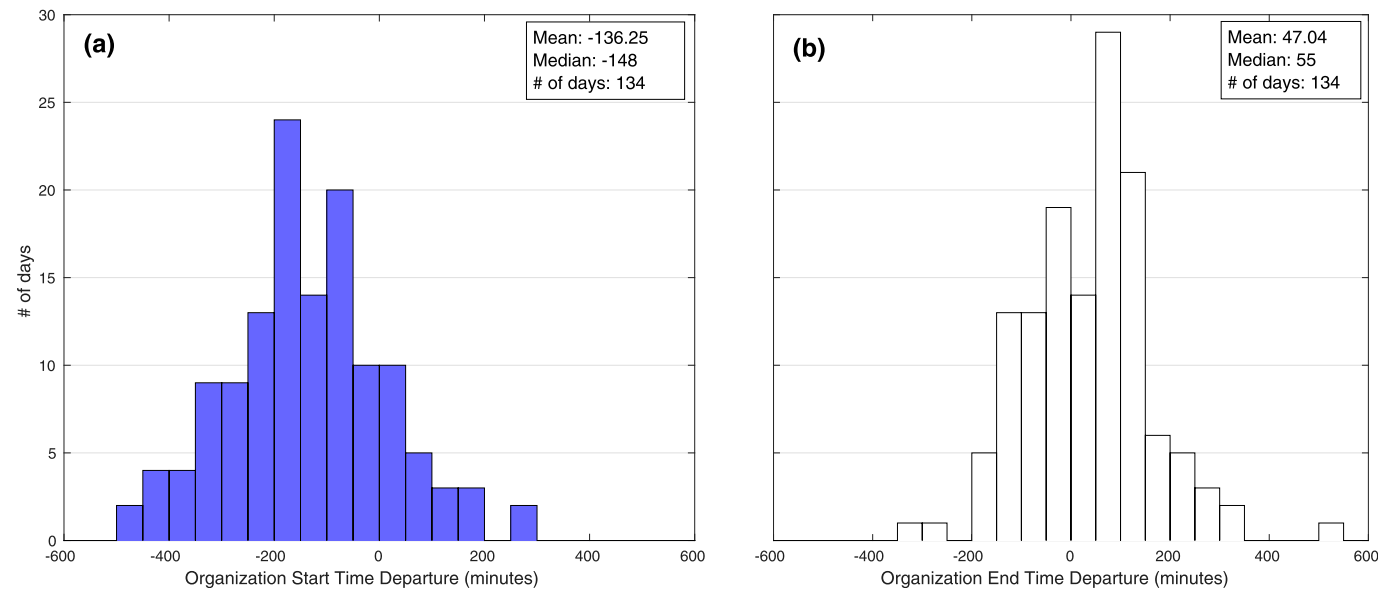

FIG. 4. Comparison of VAD RRVV analysis and manual analysis for start and end times of boundary layer organization. Boundary layer organization departure is computed as $T_{\mathrm{RRVV}}-T_{\text {manual }}$ where $T<0$ indicates RRVV analysis times are earlier than manually identified times. Note that timing from the RRVV method overestimates the range of actual boundary layer organization (i.e., RRVV analysis has earlier start times and later end times than found from the manual analysis). Departures for (a) start times and (b) end times from 134 days with boundary layer organization in 2014 are included. 
the dominant weather condition). Only days on which the RRVV method suggests boundary layer organization may be present are subjected to manual inspection in order to filter out null cases.

\section{b. Differentiating HCRs from cellular convection}

Once the possibility of boundary layer organization is diagnosed, it is desirable to differentiate between boundary layer organization and null events. Visually, HCRs and cellular convection have distinct differences (Fig. 1). HCRs are aligned in linear reflectivity patterns with much larger along-wind extent than crosswind extent. Cellular convection, however, has a more symmetric reflectivity pattern with many hexagon-like structures. Over the times when boundary layer organization is identified using the VAD RRVV threshold, reflectivity PPIs at the $1.4^{\circ}$ elevation angle are generated and visually inspected to identify the characteristics of HCRs and cellular convection. The $1.4^{\circ}$ elevation scan is used to reduce the effects of ground clutter while maximizing the range of boundary layer sampling.

Several computational methods were tested in an attempt to differentiate cellular and HCR reflectivity patterns. Autocorrelation, as in Weckwerth et al. (1997), is found to be useful for differentiating between the most ideal HCR and cellular convection cases, but it does not work as well for cases with less clear-cut or hybrid radar signatures. Ultimately, the development of robust computational methods proved time consuming and unreliable owing to the continuum over which HCRs and cellular convection manifest themselves. Instead, the identification of HCR and cell start and end time for the remainder of the climatology was conducted manually by visual inspection of all radar imagery during the interval over which boundary layer organization or a null case was suggested by the VAD RRVV method. Times were recorded for the onset of HCRs or cellular convection, transitions between both modes, and the dissipation of HCRs and cellular convection. Boundary layer organization was only recorded if rolls or cellular convection persisted for at least $30 \mathrm{~min}$. If no organization was observed, the day is classified as a null case. It is possible that organization exists on days identified as null cases, but cannot be observed on a radar. A couple possible explanations include a shallow boundary layer (leading to cells or rolls that are too small to identify) or cloud cover that results in lower reflectivity values.

After all PPI images are investigated and roll/cellular convection cases classified, a final visual check is performed using a loop of radar images each day from 1200 to 0000 UTC (0700-1900 LT, sunrise and sunset times range from 0614 to $0724 \mathrm{LT}$ and from 1915 to 2049 LT, respectively, during the warm season). This visual check has two purposes: to verify the timings of HCRs and cellular convection evolution; and to identify days on which precipitation is observed or the radar imagery is too complex to effectively classify. The latter task involves identification of the occurrence of rolls, cellular convection, precipitation, null cases, or complex features for each day. Based on these results, we then classify individual days into the following categories: rolls, cells (cellular convection), rolls to cells, cells to rolls, rolls and precipitation, cells and precipitation, precipitation, null case, and unclear. This classification process results in the climatology that is presented in section 3 .

\section{c. HCR and cell characteristics}

Investigation of hundreds of cases found $\mathrm{HCR} /$ cell evolution to be continuous such that first and last hour analysis encompasses the entire scope of HCR/cell behavior. Based on this finding and in the interest of time, the interim period of HCR and cell evolution between the first and last hour of their lifetime are not explicitly analyzed. The important properties for describing HCRs are orientation of the roll axis with respect to the mean boundary layer wind, the roll wavelength, and the roll aspect ratio. To estimate HCR wavelength and orientation, $1.4^{\circ}$ reflectivity images are produced for each volume scan within the identified HCR lifetime. The VAD method is used to identify the mean wind direction; the roll orientation with respect to the VAD wind is determined manually. HCR wavelength is also determined manually by counting the number of updraft regions over a $20-100 \mathrm{~km}$ distance, depending on the horizontal extent of HCRs. Wavelength and orientation are determined for the first and last hour of HCR lifetime. Convective boundary layer depth is estimated for the first and last hour of HCR lifetime using differential reflectivity $\left(Z_{\mathrm{DR}}\right)$, following Banghoff et al. (2018). This technique estimates the depth of the convective boundary layer based on the height of a $Z_{\mathrm{DR}}$ reduction associated with Bragg scatter that exists at the interface between the warm, dry free troposphere and the cooler, moist convective boundary layer. Finally, wavelength and boundary layer depth are used to determine aspect ratio (wavelength/boundary layer depth) for the first and last hour of HCR lifetime.

The important properties for describing cellular convection are fewer than for HCRs and include cell diameter and cell aspect ratio. Cell diameter is determined by estimating the average distance across multiple cells using $1.4^{\circ}$ reflectivity images. Convective 


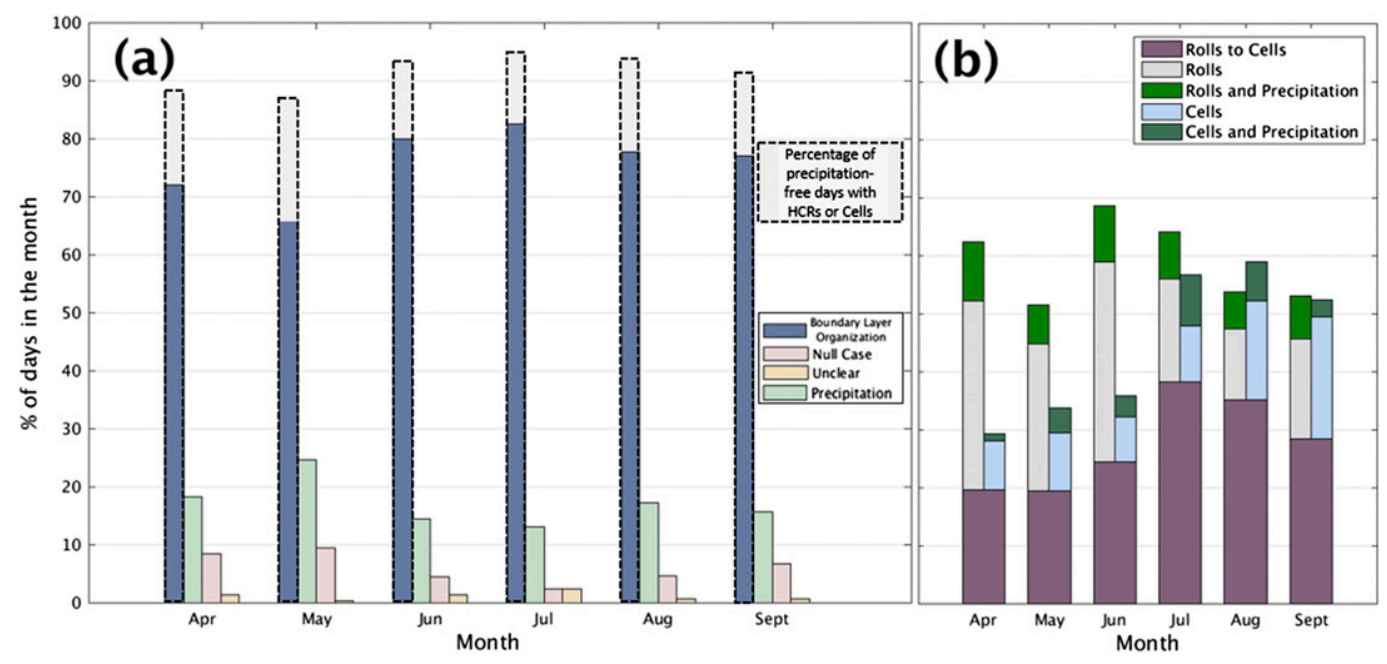

FIG. 5. (a) Cumulative 10-yr warm-season climatology of HCRs in central Oklahoma separated by month showing the percentage of days that exhibit boundary layer organization, widespread precipitation, and no or disorganized boundary layer convection (null cases), along with cases deemed indiscernible (unclear). The percentage of precipitation-free days on which boundary layer organization occurs is denoted by a black dashed column. (b) For each month, boundary layer organization days are separated into HCRs (left column) and cellular convection (right column). Transition cases (both HCRs and cells, so doubly represented), pure HCRs/cells, and a mix of organization (HCRs or cells) and precipitation are delineated. Note that a majority of days in each month have HCRs, and nearly $75 \%$ of all days have boundary layer organization.

boundary layer depth is again estimated using differential reflectivity following Banghoff et al. (2018) and aspect ratio is calculated. Cell aspect ratio is calculated for the first and last hour of cell lifetime.

\section{Results}

There are 1830 days during the months of April through September over the 10-yr period 2008-17. Of those days, 5 did not have any radar data and 18 had missing radar data for part of the day, resulting in 1807 complete days of KTLX radar data. Boundary layer organization (HCRs and/or cellular convection) is observed on 1382 days $(76 \%)$ with HCRs observed on 1072 days $(59 \%)$. The remaining days include precipitation (313 days or $17 \%$ ), null cases in which no or disorganized structure is observed (108 days or $6 \%$ ), and radar signatures that are too complex or ambiguous to effectively classify ( 20 days or $1 \%$ ). If the days with precipitation are removed, then over $92 \%$ of the remaining days have some form of boundary layer organization for part of the day.

\section{a. 10-yr climatology}

Figure 5 shows the monthly climatology for the period 2008-17. Boundary layer organization occurs on at least $66 \%$ of days in each month across the 10 -yr period, peaking at $83 \%$ in July. A majority of the days with precipitation occur in April and May (Fig. 5a).
Separating boundary layer organization by organization type reveals that HCRs occur on a majority of days in each month throughout the warm season (Fig. 5b). Additionally, about one-third of the HCRs undergo transition to or from cellular convection (Fig. 5b); these transitions happen more frequently later in the warm season, during July, August, and September.

Separating the climatology by year yields further insights (Fig. 6). July 2011 and July 2012 consist entirely of days that exhibit boundary layer organization. Additionally, 2015 has the lowest percentage of days with boundary layer organization $(66 \%)$, whereas 2011 has the largest percentage of days (87\%). July and August have the highest frequency of HCR to cellular transition cases, which is especially evident in 2010-13. It follows that these high percentage occurrences of boundary layer organization correspond with anomalously dry months/years. A majority of purely HCR days occur in the first half of the season and a majority of cellular convection days occur in the second half of the warm season. We hypothesize that this is due to generally weaker winds (as in Atkinson and Zhang 1996) and larger sensible heat flux observed in the second half of the season compared to the first half.

The majority of HCR fields last less than $4 \mathrm{~h}$, but some HCR fields can persist for longer than $9 \mathrm{~h}$ (Fig. 7). Roll duration is most commonly between 1 and $3 \mathrm{~h}$, with about $28 \%$ between 4 and $9 \mathrm{~h}$. When HCRs are the only type of boundary layer organization on a given day, 


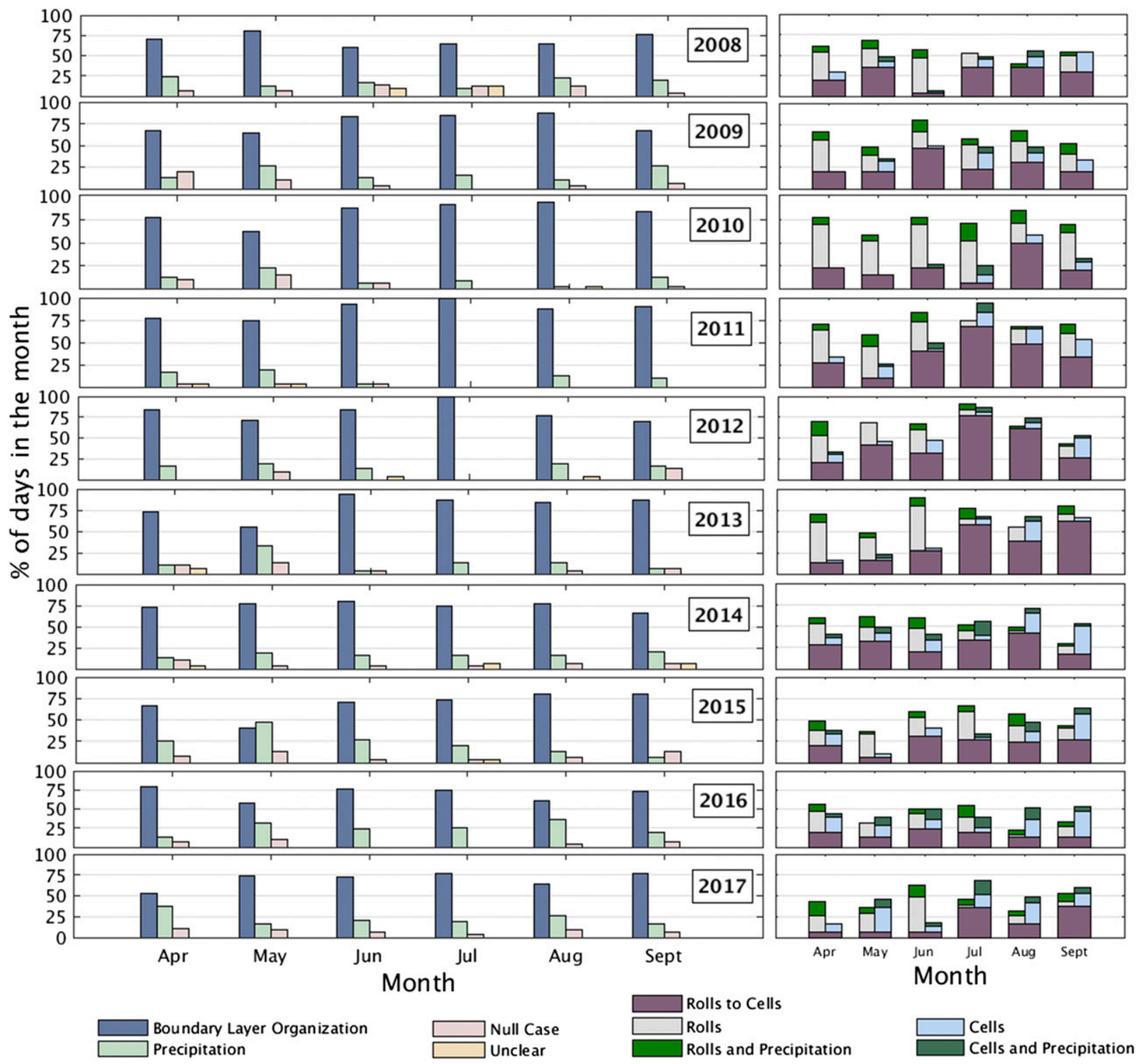

FIG. 6. (Left) Annual warm-season climatology of HCRs in central Oklahoma separated by month showing the percentage of days that exhibit boundary layer organization, widespread precipitation, and no or disorganized boundary layer convection (null cases), along with cases deemed indiscernible (unclear). (Right) For each month, boundary layer organization days are separated into HCRs (left column) and cellular convection (right column). Transition cases (both HCRs and cells, so doubly represented), pure HCRs/cells, and a mix of organization (HCRs or cells) and precipitation are delineated. Data are based on visual observation of base reflectivity between 1200 and 0000 UTC from the Twin Lakes, OK (KTLX), WSR-88D.

HCR duration is uniformly distributed from half an hour to $8 \mathrm{~h}$ with a drop off in frequency between 8 and $9.5 \mathrm{~h}$ (Fig. 7b). When HCRs undergo a transition either from or to cellular convection, the HCR field generally persists for $<4 \mathrm{~h}$ (Figs. 7c,d). Transitions from HCRs to cellular convection are more common than transitions from cellular convection to HCRs, with 415 cases of the former and 237 of the latter.

A subset of days in this climatology experience a dual transition in which rolls transition to cellular convection and then transition back to roll-like features late in the day. Of the 886 days in the 10 -yr climatology with rolls as the first mode of boundary layer organization, $14 \%$ underwent a dual-transition (12\% of all days in the $10-\mathrm{yr}$ period). In dual-transition cases, the resultant roll-like features tend to have higher reflectivities and larger wavelengths compared to those of initial roll occurrence. Such signatures may be an indication of stronger updrafts (larger concentration of lofted insects). One such example of this dual transition is discussed at the end of this section. 

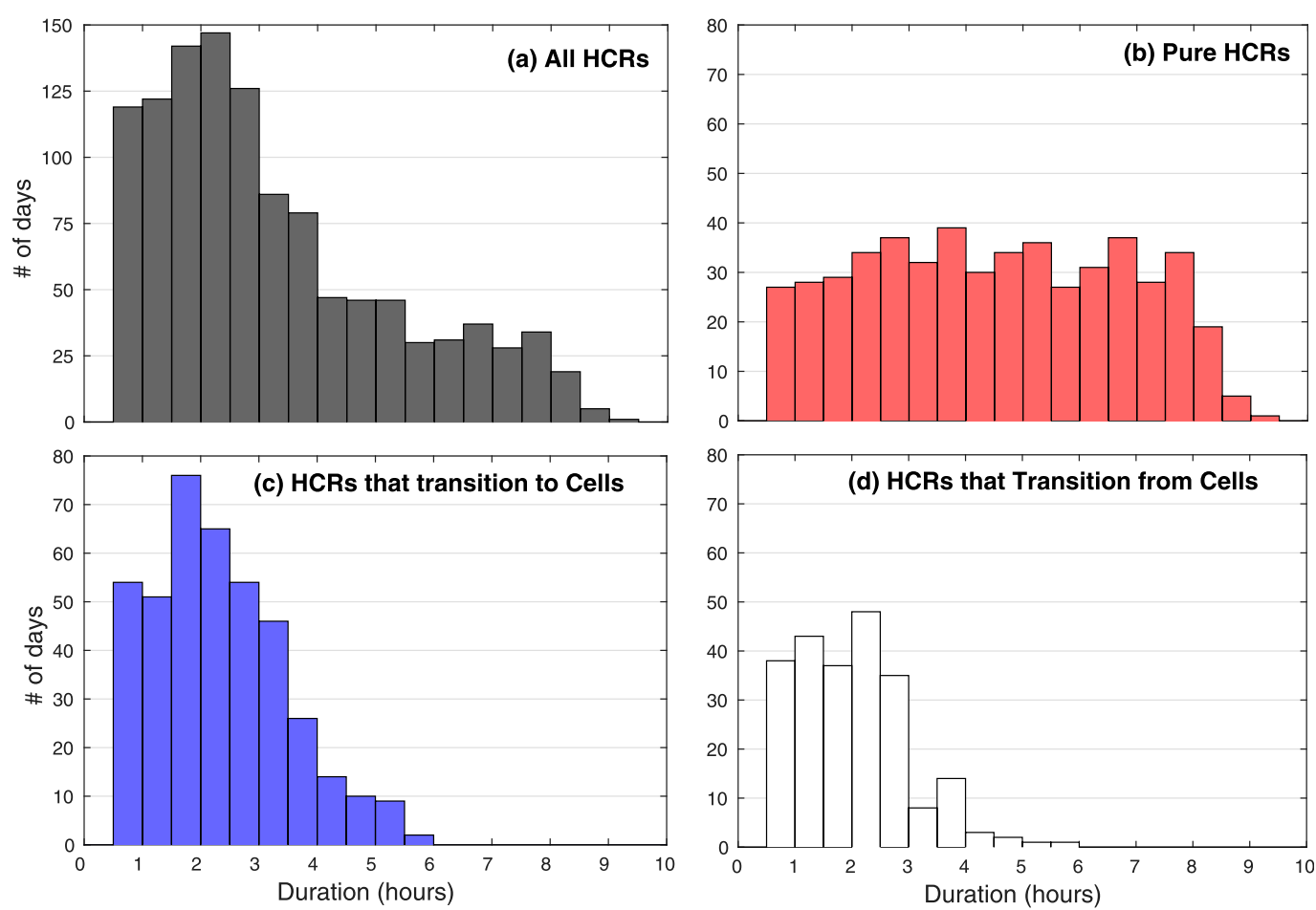

FIG. 7. HCR duration for April-September of 2008-17 at KTLX. Durations are broken down in (a) all HCR cases, (b) days where HCRs are the only boundary layer organization, (c) days when HCRs undergo transition to cellular convection, and (d) days when HCRs are formed via transition from cellular convection.

Similar to rolls, cells can exist as the only form of boundary layer convection on a given day (pure cells), transition to or from HCRs on single transition days, or form between HCR occurrences on dual-transition days. Cells are observed to persist for up to $8.5 \mathrm{~h}$ but most often last for 2-5h (Fig. 8a). Pure cells and posttransition cells account for the longest durations $(>6 \mathrm{~h}$, Figs. 8b,d) and shorter duration cases are distributed among pure cell and transition cases. Pretransition cells are less frequent (110 days, Fig. 8 c) and have shorter duration than posttransition cells (283 days, Fig. 8d). Cells that form on dual-transition days behave similarly to pretransition cell cases with comparable frequency (130 days) and duration (Fig. 8e).

Summing the values of HCR and cell duration over all events allows us to estimate the fraction of the daytime CBL influenced by boundary layer circulations. There are $\sim 24428 \mathrm{~h}$ of daylight during the 10 warm seasons in this climatology. HCRs persist for $3709 \mathrm{~h}$ equating to $15.2 \%$ of the daylight hours. Cells persist for $2946 \mathrm{~h}$ equating to $12.1 \%$ of the daylight hours. In total, boundary layer organization (rolls + cells) is present for $27.3 \%$ of daylight hours during the $10-y r$ warm season climatology. If days with precipitation are removed, then boundary layer organization is present for over $34 \%$ of daylight hours.
Analysis of HCR diurnal evolution (Fig. 9) shows that HCRs can develop as early as 1438 UTC (0938 local time) and persist past 0000 UTC (1900 local time). All HCR cases that persist after 0000 UTC are grouped in the 2300 UTC bin. Of the 137 days that exhibited boundary layer organization in 2014, organization persisted after 0000 UTC on 42 days. Of these days, boundary layer organization only persisted past 0100 UTC on 1 day. Owing to the organization and download process of WSR-88D data, it is assumed for simplicity that boundary layer organization dissipates around 0000 UTC. Based on the aforementioned 2014 analysis, error acquired by this assumption is considered negligibly small. HCRs formed as late as 2200 UTC, corresponding to very short-duration HCR events. After formation, some HCRs undergo a transition to cellular convection, most often in the early afternoon (1700-1900 UTC; 1200-1400 LT). Cellular convection also can transition to HCRs, often late in the day. About half of the observed cases of transition from cellular convection to HCRs occur on days when HCRs are the first mode of boundary layer organization earlier in the day. The other half of HCR cases develop after cellular convection is the first mode of boundary layer organization. Finally, HCRs and cellular convection 

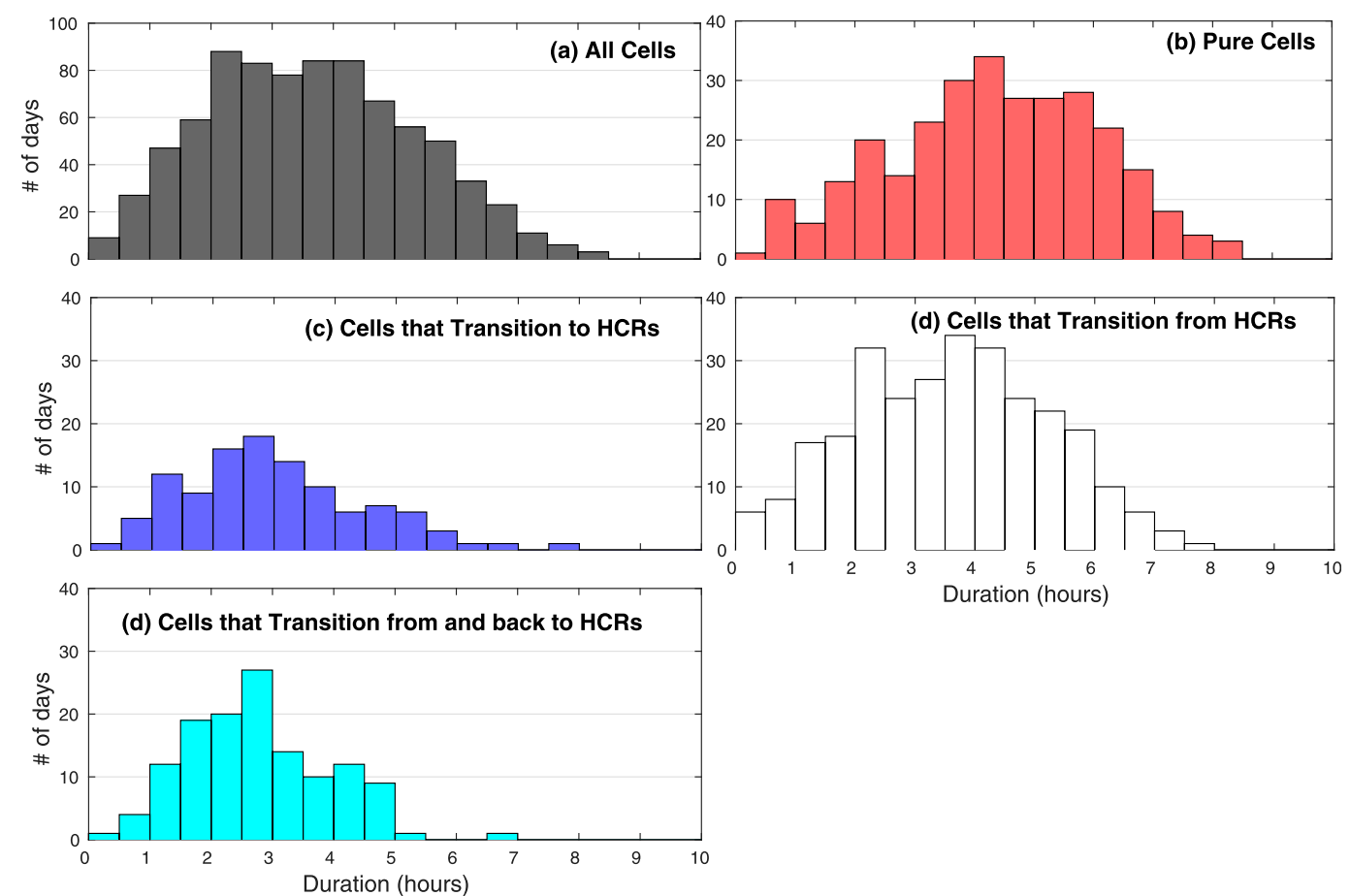

FIG. 8. Cellular convection duration for April-September of 2008-17 at KTLX. Durations are broken down in (a) all cell cases, (b) days where cells are the only boundary layer organization, (c) days when cells undergo transition to HCRs, (d) days when cells are formed via transition from HCRs, and (e) days when cells form from HCRs and then transition back to HCRs.

dissipate (reflectivity pattern disappears) around sunset as surface heating subsides and boundary layer convection is no longer sustained. Sunset times in central Oklahoma during the warm season range from 0015 to 0149 UTC (1915 to 2049 LT).

\section{b. Results from 2013 to 2017}

For the analysis of HCR orientation, HCR horizontal wavelength, cell diameter, and HCR and cell aspect ratio, only data from 2013 to 2017 are used. These years have a complete set of dual-polarization radar data available, which facilitates estimation of boundary layer depth using differential reflectivity $\left(Z_{\mathrm{DR}}\right)$ following the methods of Banghoff et al. (2018). Because dualpolarization radar was not implemented at KTLX until October 2012, the years 2008-12 are excluded from the orientation, wavelength, diameter, and aspect ratio analysis.

HCR characteristics have been investigated in numerous case studies, and observations of HCR wavelength, boundary layer depth, and roll orientation reported. A summary of results from several representative previous studies is shown in Table 1. HCRs have previously been observed with horizontal wavelengths ranging from 2 to $18 \mathrm{~km}$, boundary layer depths from 0.6 to $2.2 \mathrm{~km}$, aspect ratios of $1-13$, and orientation angles generally within $10^{\circ}$ of the mean boundary layer wind. For the sake of comparison, it is important to note that many of the listed HCR observations are from studies of cold air outbreaks over water in the midlatitudes. Based on the work of

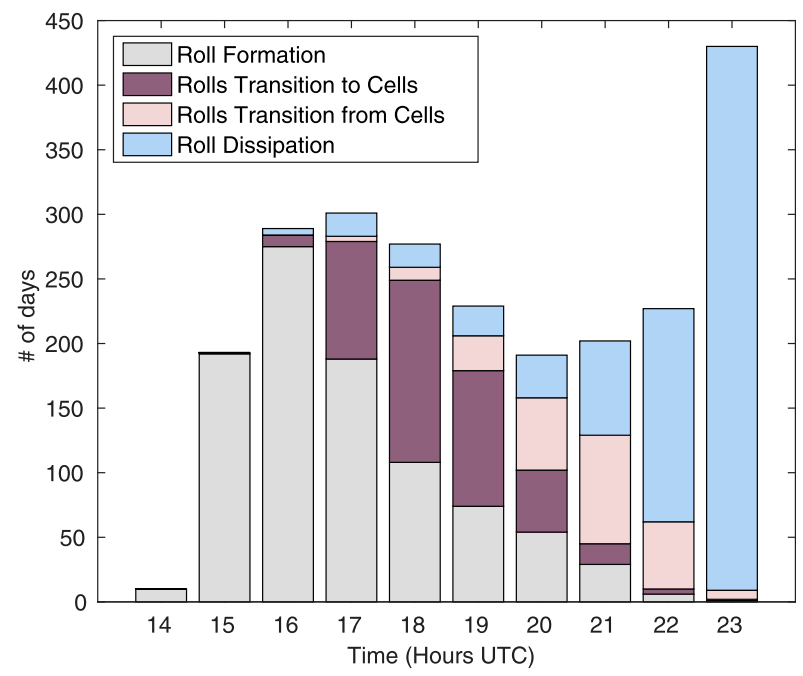

FIG. 9. Histogram of HCR timing during the warm season from 2008 to 2017 at KTLX. All HCR cases that persist after 0000 UTC are grouped in the 2300 UTC bin (42 cases in 2014 with only 1 case persisting after $0100 \mathrm{UTC})$. 
TABLE 1. Summary of horizontal convective roll case studies. As shown here, $\varepsilon$ is counterclockwise from inversion level geostrophic wind and $\varphi$ is counterclockwise from mean BL wind.

\begin{tabular}{|c|c|c|c|c|c|}
\hline Reference & Nature of study & $\begin{array}{l}\text { Wavelength } \\
(\mathrm{km})\end{array}$ & $\begin{array}{l}\text { PBL depth } \\
\quad(\mathrm{km})\end{array}$ & $\begin{array}{l}\text { Aspect } \\
\text { ratio }\end{array}$ & $\begin{array}{c}\text { HCR } \\
\text { orientation }\end{array}$ \\
\hline Angell et al. (1968) & Radar tracking of tetroons in SE Idaho, clear air & 4 & 1.4 & 2.9 & $\varepsilon=19$ \\
\hline Atlas et al. (1983) & Cold air outbreak in NY and NJ & $3-10$ & $1.0-1.4$ & $3-7$ & $\varphi=0$ \\
\hline Atlas et al. (1986) & $\begin{array}{l}\text { Cold air outbreak along the coasts of the } \\
\text { mid-Atlantic states }\end{array}$ & $1-2$ & $0.6-0.8$ & $1.3-3.3$ & $\varphi=0$ \\
\hline Berger and Doviak (1978) & Dual-Doppler radar data near Norman, OK & 4 & 1.5 & 2.7 & $\phi=20$ \\
\hline Hildebrand (1980) & Dual-Doppler radar data from central Oklahoma & $4-4.8$ & $1-1.4$ & $3.4-4$ & $\varphi=0$ \\
\hline Kelly (1982) & Lake-effect snow over Lake Michigan & $3.5-7.5$ & 1.3 & $2.7-5.8$ & $\varepsilon=0$ \\
\hline Kelly (1984) & Cold airflow over Lake Michigan & $1.5-13.7$ & $0.9-2.1$ & $1.0-9.1$ & $\varepsilon=-10$ to 10 \\
\hline Kropfli and Kohn (1978) & Dual-Doppler radar data near St. Louis, MO & 5 & - & - & - \\
\hline Kuettner (1971) & $\begin{array}{l}\text { Measurements from satellite photos and raobs } \\
\text { over tropical Atlantic, Florida, Wisconsin, } \\
\text { Gulf of St. Lawrence, and Georgia }\end{array}$ & $2-8$ & $0.8-2$ & $2-4$ & $\varepsilon=0-10$ \\
\hline LeMone (1973) & $\begin{array}{l}\text { Tower and/or aircraft probes over Great Lakes } \\
\text { and in Oklahoma; clear air }\end{array}$ & $1.3-6.5$ & $0.6-2.3$ & $2.16-6.5$ & $\varepsilon=10-20$ \\
\hline Reinking et al. (1981) & Dual-Doppler radar data near Chickasha, OK & $2-6$ & $1.1-1.5$ & Avg: 2.7 & $\varphi=10-20$ \\
\hline Weston (1980) & $\begin{array}{l}\text { Visible satellite imagery and rawinsondes over } \\
\text { England }\end{array}$ & $2.5-9$ & - & Avg: 3.2 & $\varphi=-25-25$ \\
\hline Yang and Geerts (2006) & Cold airflow over Lake Michigan & $2.5-18$ & $1.1-1.37$ & $2-13$ & $\varphi=-10$ \\
\hline
\end{tabular}

Atkinson and Zhang (1996) and Young et al. (2002), it is expected that such cool-season cases would have somewhat larger wavelengths and aspect ratios compared to warm-season cases. Overland warm-season cases in previous studies have exhibited wavelengths of $2-6.5 \mathrm{~km}$ and aspect ratios around 3.1 .

The environmental wind direction on HCR days and HCR orientation angle departure from the mean wind direction for the warm seasons of 2013-17 are shown in Fig. 10. Wind directions are computed using the VAD method with radial velocities averaged over the range of $15-25 \mathrm{~km}$ from the radar corresponding to a beam height of $0.39-0.66 \mathrm{~km}$. Using this shallow layer to estimate the mean boundary layer wind is a convenient simplification based upon the assumption that winds in the boundary layer are well-mixed. When wind shear is large in the boundary layer this assumption is not valid and may contribute to some of the larger orientation angle departures in Fig. 10. Note that the radar detects the motion of insects, not necessarily the wind
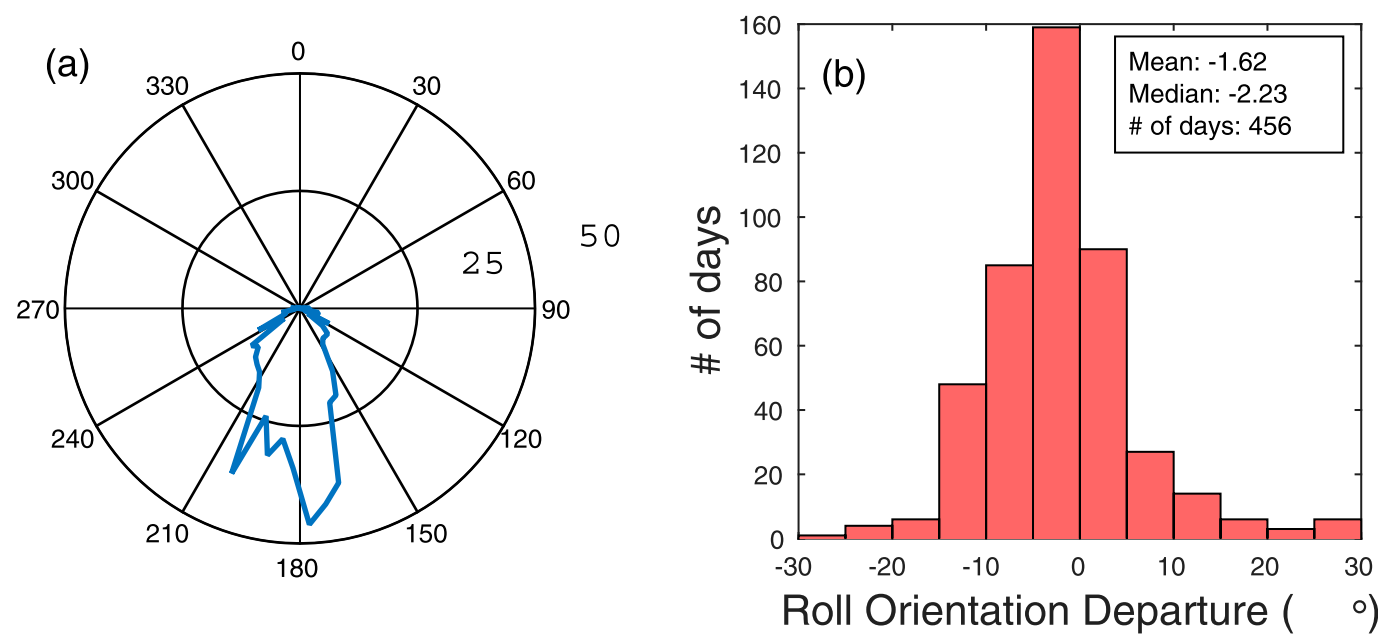

FIG. 10. (a) Wind direction calculated from the VAD wind at the onset of HCRs each day from April-September 2013-17 at KTLX. Radial distance indicates number of days exhibiting each wind direction. (b) Histogram of the departure of HCR orientation from the mean wind direction for the days. Positive values indicate HCR orientation is to the right of the mean wind (counterclockwise). Note that there are 6 cases with departures above $30^{\circ}$ not exceeding $50^{\circ}$ (not shown). 
(Vaughn 1985; Drake and Farrow 1988; Chapman et al. 2011). If insects are not passive tracers, which is possible for large insects such as locusts and butterflies, the radar wind vector is influenced by migration direction and may not accurately represent wind direction. A majority of wind directions on HCR days occur near $180^{\circ}$ with a peak just below $180^{\circ}$, corresponding to south-southeasterly flow. These wind directions are typical of warm-season wind direction distributions in central Oklahoma (U.S. Department of Agriculture National Water and Climate Center 2019).

HCR orientation angle departure is computed by taking the VAD mean wind direction minus the HCR orientation angle. Positive values indicate HCR orientation counterclockwise from the mean wind. Results show that the average HCR alignment is slightly to the left of the mean wind (clockwise, negative departure values) with $98 \%$ of cases exhibiting orientation departures $<30^{\circ}$, and $79 \%$ aligning within $10^{\circ}$ (Fig. 10). There were 6 cases with orientation departures greater than $30^{\circ}$ (not shown) but none exceeded $50^{\circ}$. Some of the large departures may result from an incomplete estimate of boundary layer wind if the fixed layer is unrepresentative of the boundary layer. The orientation angle departure distribution is approximately symmetric around $0^{\circ}$, suggesting there is not a preferred departure in the counterclockwise or clockwise direction. HCR orientation departures in the present study mirror previous HCR review papers (Atkinson and Zhang 1996; Young et al. 2002) and case studies listed in Table 1.

For the present study, the wavelength and aspect ratio analysis is separated into three categories: pure HCRs (241 cases), HCRs before transition to cellular convection (pretransition, 175 cases), and HCRs after transition from cellular convection (posttransition, 103 cases) for a total of 519 HCR cases on 390 days (129 days with HCRs before and after cellular convection). This separation allows detection of important differences between the three types of HCR manifestation. Wavelength and aspect ratio values for the first and last hour of roll duration are investigated (Fig. 11).

HCR wavelengths are generally between 2 and $8 \mathrm{~km}$ in the first hour across all modes (Figs. 11a,e,i). All modes undergo an increase in wavelength with time from the first to last hour of duration (Figs. 11b,f,j). The expansion of HCR wavelength during the day is well-documented (Atlas et al. 1983; Chang and Shirer 1984; Miura 1986). HCRs that occur before a transition to cellular convection have the shortest average wavelengths throughout their life cycle $(2.66 \mathrm{~km}$ in the first hour and $3.32 \mathrm{~km}$ in the last hours; Figs. 11e,f), likely because these HCRs occur earlier in the day when boundary layer depth is shallower. In contrast, HCRs that form after transition from cellular convection have the largest average wavelengths throughout their life cycle $(4.53 \mathrm{~km}$ in the first hour and $6.97 \mathrm{~km}$ in the last hour; Figs. 11i,j). HCRs have wavelengths of up to $30 \mathrm{~km}$, but most wavelengths are $<10 \mathrm{~km}$. There were a total of $44 \mathrm{HCR}$ cases with wavelengths $>$ $10 \mathrm{~km}$ ( 2 pretransition cases, 19 pure HCR cases, 1 before transition, and 22 after transition; total of $8.5 \%$ of all HCR cases) and wavelengths $>20 \mathrm{~km}$ occurred on 7 days (6 pure HCR and 1 after transition; $1.3 \%$ of all HCR cases) with all of such HCRs observed after 2200 UTC. This result suggests that the upper bound of HCR wavelength is not dependent on the number of transitions between modes of boundary layer organization in a given day.

The 44 cases with wavelengths exceeding $10 \mathrm{~km}$ diverge from the narrow rolls associated with overland cases as described in Atkinson and Zhang (1996). These observations also exceed values previously reported for overland cases, and are more characteristic of wavelengths associated with wide-roll HCR cases over water during the cold season in the midlatitudes or summertime in the tropics (LeMone and Meitin 1984; Kelly 1984; Atkinson and Zhang 1996; Young et al. 2002; Yang and Geerts 2006; Melfi and Palm 2012). That some overland HCR cases have wavelengths characteristic of wide mode rolls is novel. Additionally, the overlap in HCR characteristics between overland and cold-season overwater cases across the entire continuum of wavelengths further supports the idea that HCR structure is similar across narrow and wide mode rolls as suggested by Young et al. (2002). Another possible explanation for these large wavelengths may be the presence of gravity waves above the convective boundary layer as described by Clark et al. (1986) and documented by LeMone and Meitin (1984) in the tropics during the warm season. Rolls generated from or modified by gravity waves have a distinct structure from rolls generated through other means, but observing their differences using only radar plan-position indicator imagery as in this study is difficult.

Observed aspect ratios are generally between 1 and 8 and less variable than wavelength across the three modes (Figs. 11c,d,g,h,k,l). Aspect ratios increase from the first hour to last hour of HCR duration for pure and posttransition HCRs (3.12 in the first hour and 3.94 in the last hour for 232 pure HCR cases; 2.92 in the first hour and 4.28 in the last hour for 101 posttransition HCR cases). This implies that wavelength increases by a larger proportion than boundary layer depth during pure and posttransition HCR lifetime. The aspect ratios of pretransition HCRs decrease through HCR lifetime (3.48 in the first hour and 2.54 in the last hour for 172 pretransition HCR cases; Figs. 11g,h), implying that wavelength increases by a lesser proportion than boundary layer depth. Aspect ratios up to 

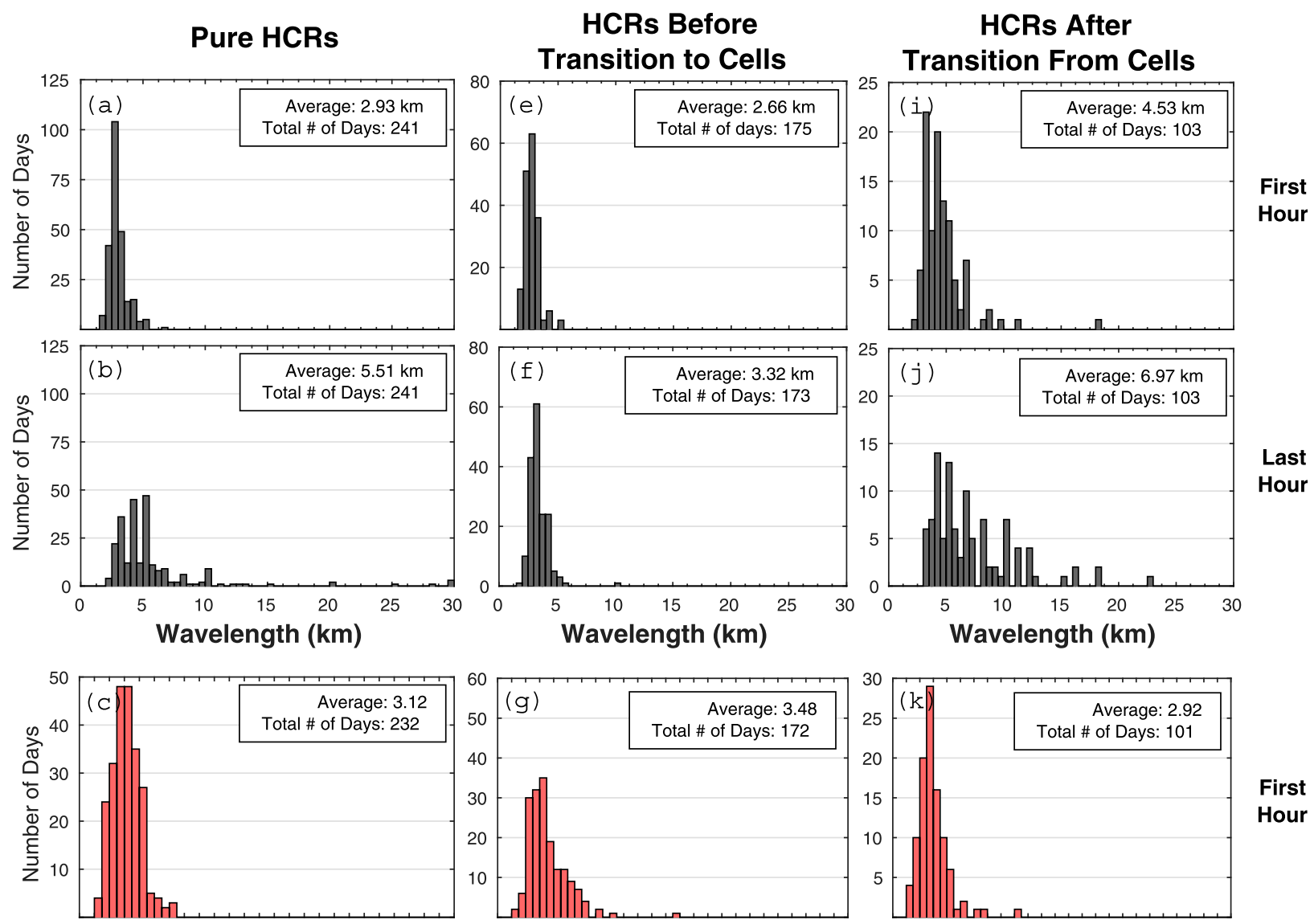

First
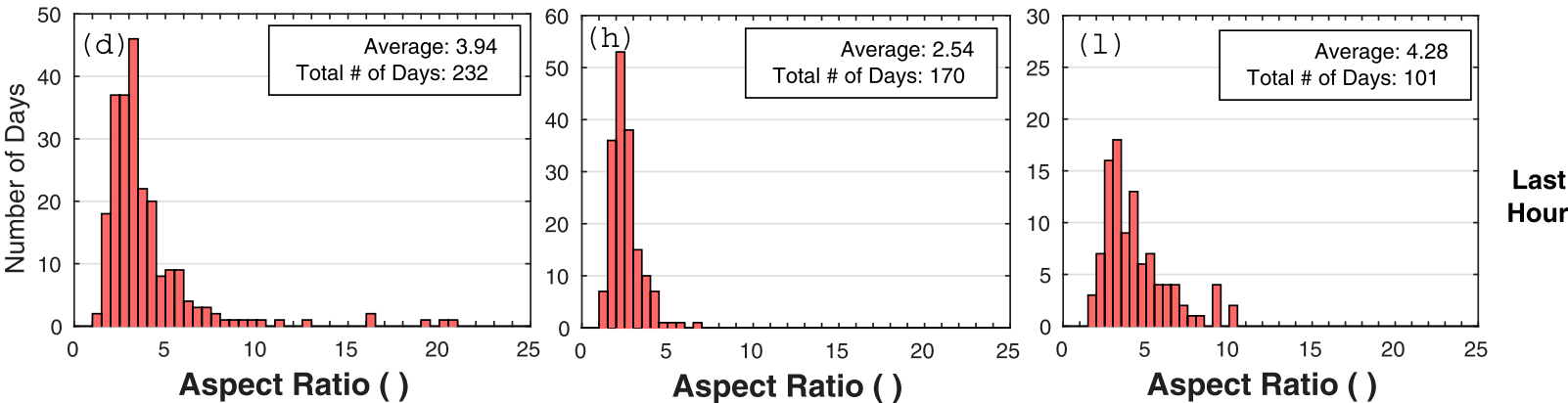

FIG. 11. Histograms of HCR wavelength and aspect ratio for all HCR days during the warm seasons of 2013-17 at KTLX. First and last hour wavelength and aspect ratio are plotted for pure (a)-(d) HCR cases, (e)-(h) HCR cases that transition to cellular convection, and (i)-(l) HCR cases that transition from cellular convection.

22 are observed, with aspect ratios $>10$ in 11 cases $(1$ first hour HCR before transition, 9 last hour pure HCRs, and 2 last hour HCRs after transition; $2.1 \%$ of all HCR cases).

A temporal analysis of wavelength and aspect ratio provides a clear understanding of the evolution of and interaction between the two variables (Fig. 12). There is a clear upward trend in wavelengths from 1500 to 2300 UTC for all HCR cases in 2013-17 (Fig. 12a) as expected as the convective boundary layer depth increases. The time series of aspect ratio, however, demonstrates a clear and unexpected three-part daytime trend (Fig. 12b). Aspect ratio is at a maximum (on average) early in the morning during the first hour of roll formation and then decreases, reaching a minimum near the value of $2 \sqrt{2}$ predicted by linear theory (Kuettner 1971; Asai 1972; Brown 1980) and staying constant through the afternoon (1700-2100 UTC; 1200-1600 LT; Fig. 12b). Toward the end of the day (2100-2300 UTC; 1600-1800 LT), aspect ratio increases. Previous overland cases reported by Young et al. (2002) had aspect ratio that was approximately constant at a value of $2 \sqrt{2}$ (their Fig. 4). The average aspect ratio 

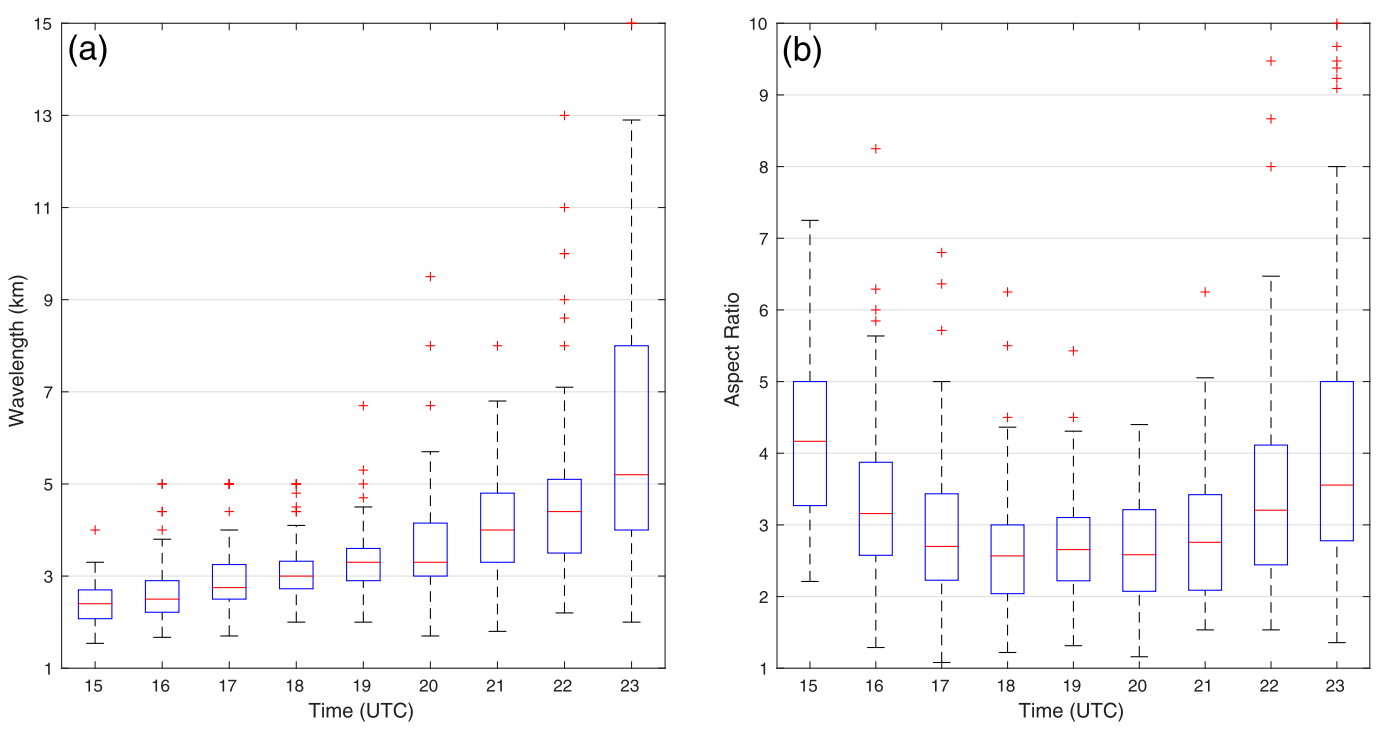

FIG. 12. Time series of box-and-whisker plots for HCR (a) wavelength and (b) aspect ratio for all HCR days during the warm seasons of 2013-17 at KTLX. The number of cases for each hour is as follows: before 1600 UTC: 58; 1600-1659 UTC: 127; 1700-1759 UTC: 134; 1800-1859 UTC: 119; 1900-1959 UTC: 90; 2000-2059 UTC: 100; 21002159 UTC: 93; 2200-2259 UTC: 110 ; after 2300 UTC: 220 . Note that 7 cases have wavelengths above $15 \mathrm{~km}$ and 8 have aspect ratios above 10 after 2300 UTC (not shown).

between 1700 and 2100 UTC is approximately $2 \sqrt{2}$, which matches previous observations, whereas the early and late parts of the day diverge from previous studies. A possible explanation for this is their reliance on satellites to survey the boundary layer. Satellites are unable to observe HCRs in the absence of cloud streets (presumably before 1700 UTC) and as sunset approaches (after 2100 UTC). As such, the results presented in Fig. $12 \mathrm{~b}$ are consistent with previous studies but suggests that other processes also are influencing roll structures early and late in the day.

Combining aspect ratio values from all three modes and separating by month yields information about the seasonal variability of HCRs (Fig. 13). There are between 59 and 106 cases from each month. During the first hour of HCR evolution, there is a gradual increase in aspect ratio from April until July followed by a drop off in August and September. Aspect ratio values for the last hour have a similar monthly trend with an increase from April until July followed by a decrease. Notably, mean aspect ratio increases from the first hour to last hour of HCR duration in 5 of 6 months (excluding May; Fig. 13). Last-hour boundary layer depth exhibits a similar trend to those of the first hour, with a decrease from April until August and an increase thereafter. The cases from May again deviate as boundary layer depth is less than that of April and June.

Weckwerth et al. (1997) show HCR wavelength and boundary layer depth (their Fig. 17) for a variety of case studies. This plot is duplicated here as Fig. 14, along with the idealized relationship from Kuettner (1971) that assumes an aspect ratio of $2 \sqrt{2}$ based on theoretical calculations using critical Rayleigh number. Results from the present study are overlaid and indicate that first hour HCRs often exhibit larger aspect ratios than those in either of the previous studies. Observed values remain within the range of aspect ratios reported in the literature (Table 1), with the last hour HCR characteristics having more spread. It appears there may be a bimodal aspect ratio trend for all HCR cases: the first follows the line found by Weckwerth et al. (1997), and the second follows a line with a slope that is slightly shallower than that of Kuettner (1971). Perhaps the most significant outcome from this analysis is the observation that aspect ratio is not constant for overland rolls as previously suggested by Young et al. (2002). This result implies there are variables aside from or in addition to aspect ratio that could help explain the daytime evolution of HCRs.

Cellular convection occurred on 387 days during the warm seasons of $2013-17$ and can be divided into 4 different occurrence modes: pure cells ( 165 cases $)$, cells that occur before a transition to HCRs (48), cells after a transition from HCRs (119), and cells that occur in between HCRs on a dual-transition day (55). For all cellular convection, aspect ratios generally are in the range of $1-5$ with a mean value between 2 and 3 , as observed in earlier studies (Hardy and Ottersten 1969; Konrad 1970). There is minimal variability among the four modes in terms of diameter (not shown) or aspect 
First Hour
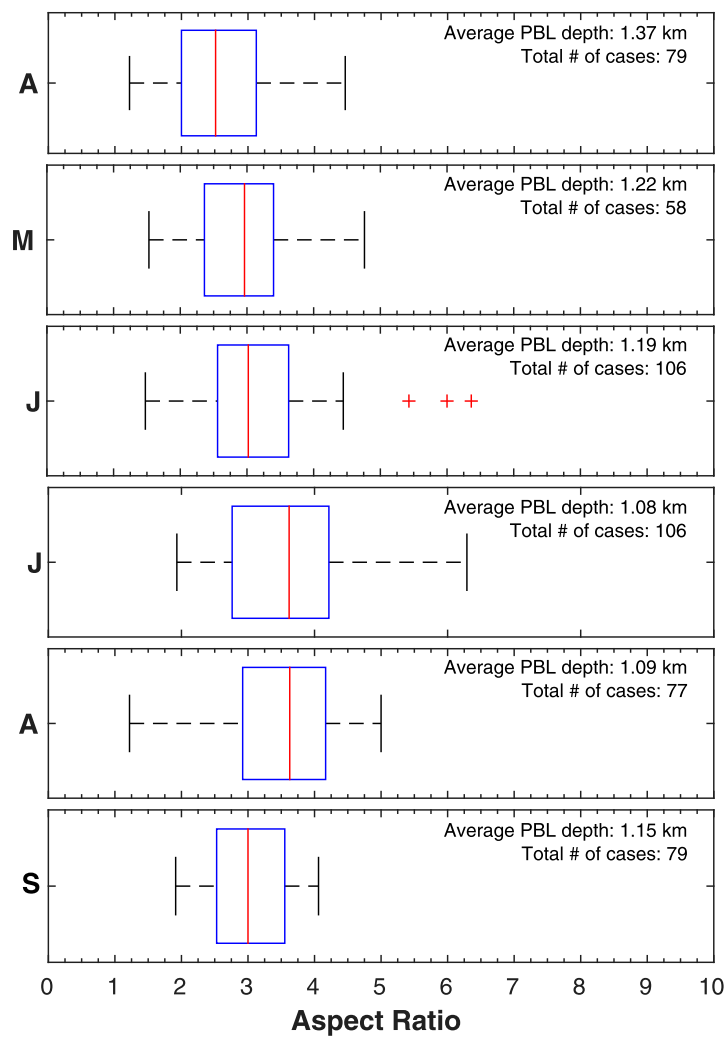

Last Hour
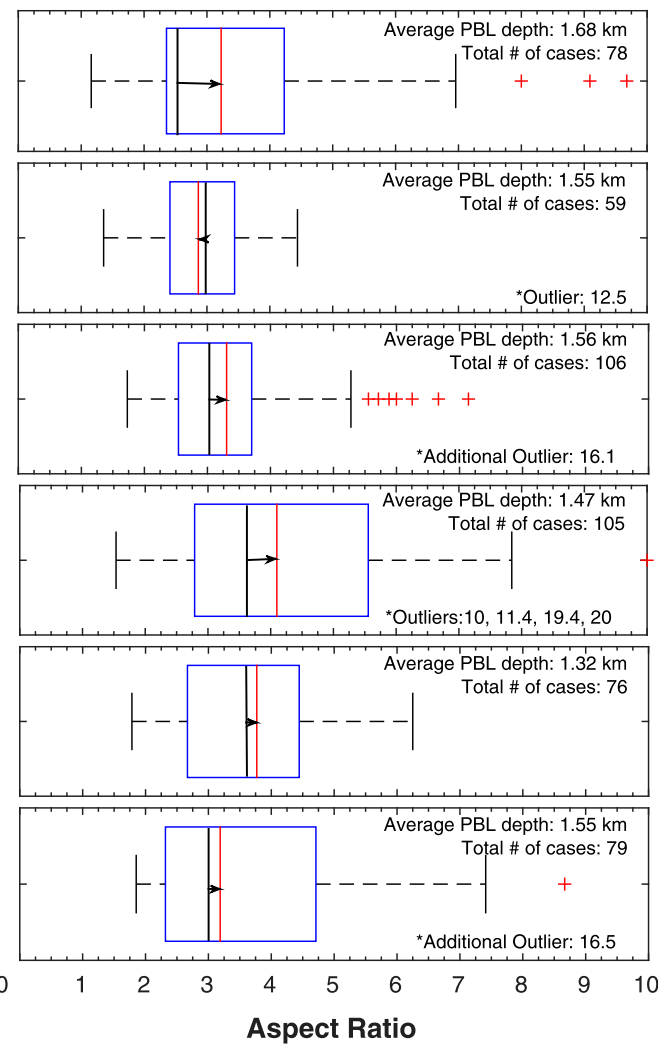

FIG. 13. Box-and-whisker plot of aspect ratio in the first hour of HCR activity and the last hour of HCR activity prior to any transition for each day and grouped by month for 2013-17 (A = April, M = May, J = June, $\mathrm{J}=\mathrm{July}$, $\mathrm{A}=$ August, $\mathrm{S}=$ September). The corresponding average monthly boundary layer depth estimates are listed in the top right of each figure. Vertical black lines on the right figures correspond to the mean aspect ratio during the first hour. The black arrow denotes the change in aspect ratio from first hour to last hour.

ratio (Fig. 15). Observed aspect ratios were between 1.09 and 8.33 with only $14 \%$ of cases exceeding 4 . Aspect ratio increased through cell lifetime for $38 \%$ of cases and decreased for $60 \%$ of cases. Typical cell aspect ratios right before transitioning to rolls were 2.5 with a range of 1.6-4. Some days are dominated by cells with aspect ratios near one and a circular reflectivity structure, suggestive of rising thermals within the boundary layer that are as wide as the boundary layer is deep, whereas other days have cells with a variety of aspect ratios. Cells with larger aspect ratios tend to have a more rectangular or hexagonal structure. This could simply reflect where in their vertically changing structure (Stull 1988) the radar beam intersected the thermals.

Thus far, narrow HCRs, cellular convection, and transitions between the two have been discussed. A case study is used to illustrate these various modes and to show differences between narrow HCRs and the observed overland wide rolls that occur late in the day. The case study should also help lay the framework for future investigation of boundary layer organization using radar data with a well-defined example of HCRs that undergo a dual transition to cellular convection and then back to HCRs. Although several days in 2013-17 could have been used to illustrate this boundary layer evolution, 4 June 2015 is selected based on the clarity of radar and satellite data.

The high temperature on this day was $32^{\circ} \mathrm{C}$, with mostly sunny skies and no precipitation. Winds were from the south at $5-7 \mathrm{~m} \mathrm{~s}^{-1}$ with gusts to $12 \mathrm{~m} \mathrm{~s}^{-1}$. No surface fronts were in the vicinity. Radar and visible satellite imagery from three different times on 4 June 2015 in central Oklahoma depict the mean boundary layer organization structures (Fig. 16). At approximately 1715 UTC, the KTLX radar begins to show an HCR pattern in reflectivity at the $0.5^{\circ}$ elevation scan (Fig. 16a). These linear features are oriented approximately south-southwestnorth-northeast along the mean wind direction. The wavelength of these HCRs is approximately $2.5 \mathrm{~km}$. At this point in the day, the boundary layer depth is $0.9 \mathrm{~km}$, 


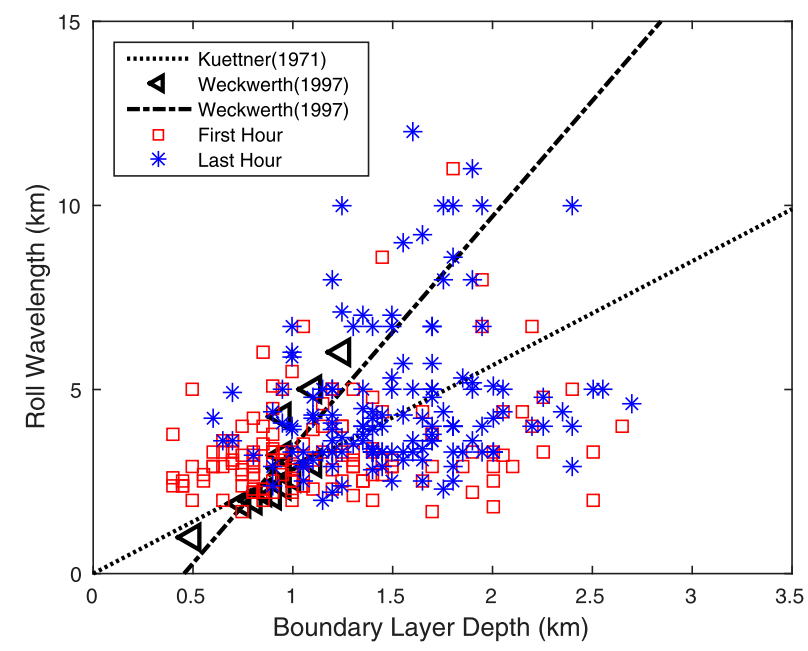

FIG. 14. Boundary layer depth vs roll wavelength as in Weckwerth et al. (1997) (their Fig. 17). Plotted are the theoretical line from Kuettner (1971), best-fit line from Weckwerth et al. (1997), and observations of HCRs in central Oklahoma during 2013-17. The slope of each best-fit line, which represents aspect ratio, is $2 \sqrt{2}$ and 5.7 , respectively.

yielding an aspect ratio of 2.8. Given that the LCL was approximately $1500 \mathrm{~m}$, boundary layer circulations are not deep enough to produce clouds at this time, as confirmed in visible satellite imagery (Fig. 16d).
A few hours later, at approximately 1946 UTC, the boundary layer depth is $\sim 1.5 \mathrm{~km}$ and radar reflectivity shows various nonlinear patterns of enhanced reflectivity characteristic of cellular convection (Fig. 16b). The oval updraft regions of enhanced reflectivity (observable in the SW quadrant in particular) indicate that cellular convection has begun and HCR transition has occurred or is occurring. Note that linear features are still evident in the reflectivity field, but there are fewer coherent linear downdraft regions. The radar image at 1946 UTC illustrates the challenges of applying automation to HCR versus cellular convection discrimination. It is difficult even for the human eye to differentiate between modes. The visible satellite imagery at 1945 UTC shows cloud streets have developed across the eastern half of Oklahoma. Approximately half of the radar domain encompasses the area where clouds have formed (Fig. 16e).

As sunset approaches (2320 UTC), the mode of boundary layer organization shifts again, this time back to HCRs, with wavelengths closer to those of wide rolls as in Atkinson and Zhang (1996). Enhanced reflectivity regions aligned south-north are now thicker and farther apart than earlier in the day (Fig. 16c). The wavelength of these rolls is approximately $9 \mathrm{~km}$ (aspect ratio of 5.3). At this point, cloud streets have dissipated across most
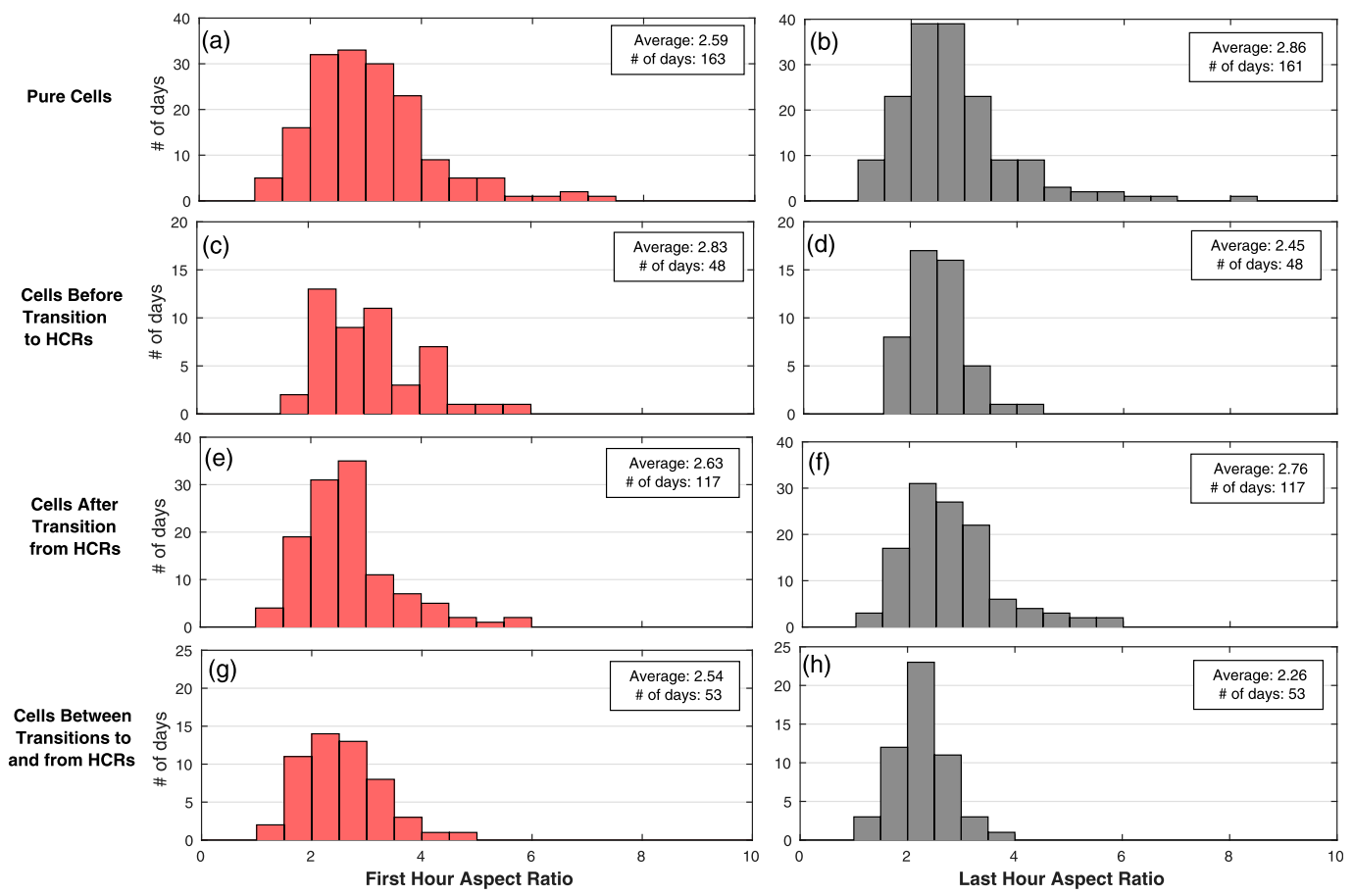

FIG. 15. Histograms of cell aspect ratio for all cell days during the warm seasons of 2013-17 at KTLX. First and last hour aspect ratio are plotted for (a),(b) pure cell cases, (c),(d) cell cases that transition to HCRs, (e),(f) cell cases that transition from HCRs, and $(\mathrm{g}),(\mathrm{h})$ cell cases that occur between HCRs on dual-transition days. 


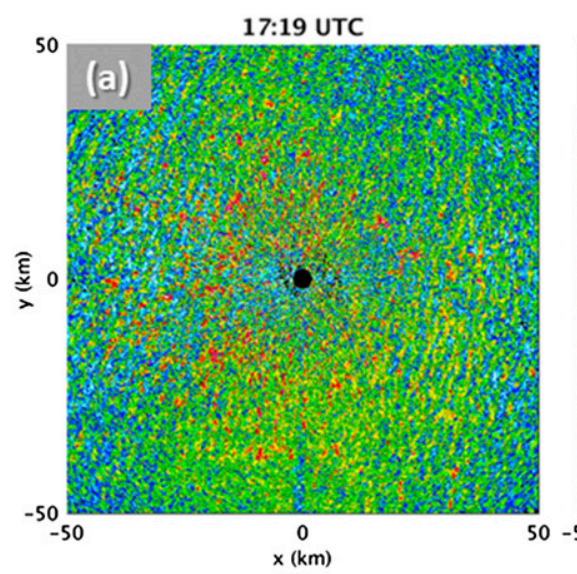

17:15 UTC

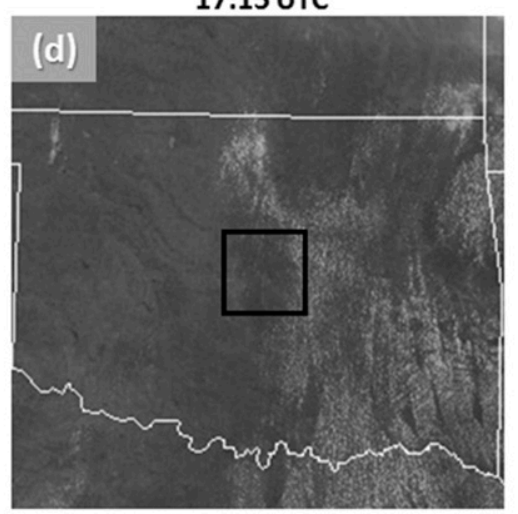

$19: 46$ UTC

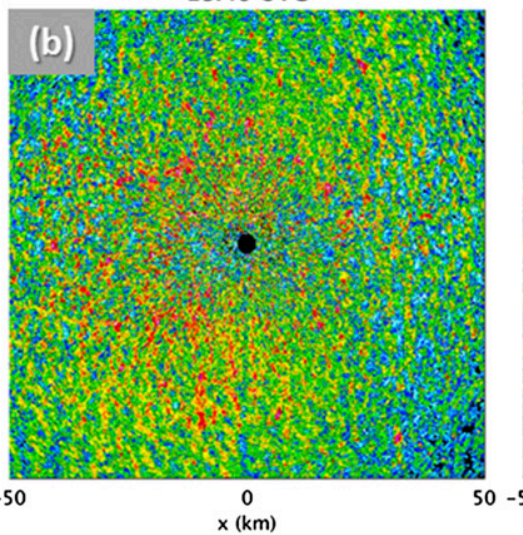

19:45 UTC

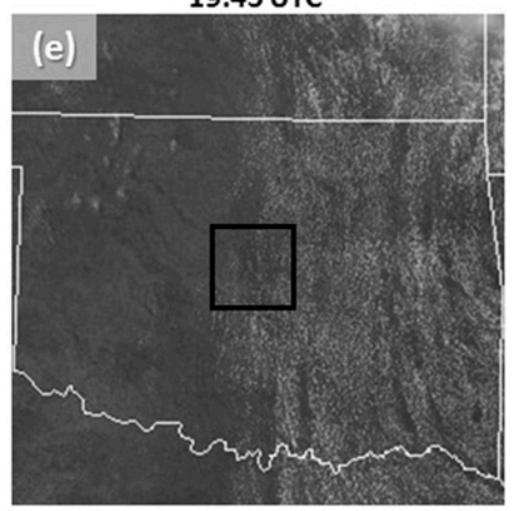

23:20 UTC

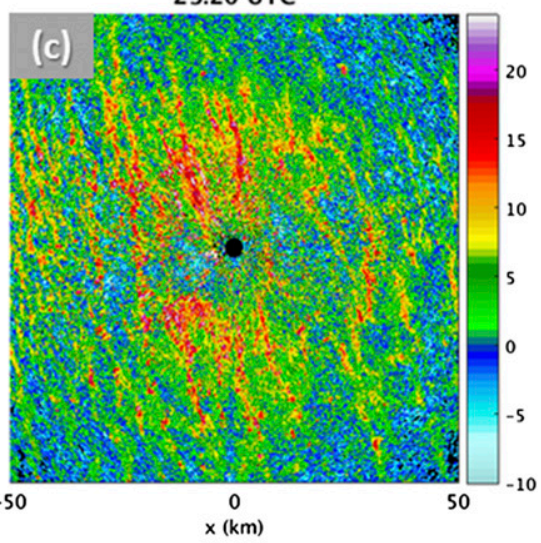

23:15 UTC

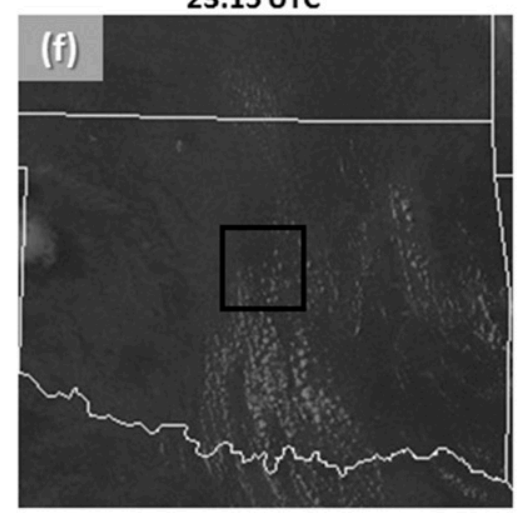

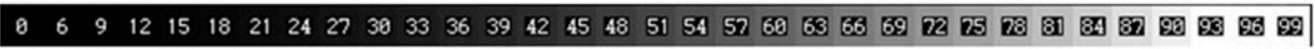

FIG. 16. Case study of boundary layer organization on 4 Jun 2015 at KTLX. (a)-(c) Reflectivity and (d)-(f) visible satellite imagery at the corresponding time. Note the transition from HCRs to cellular convection and back to HCR-like organization, except with a much larger wavelength. Black box represents the radar domain.

of eastern Oklahoma, but clouds have formed across south-central Oklahoma with a classic "string-of-pearls" structure as discussed in Kuettner (1971) (Fig. 16f).

Dual-transition cases, like the one presented in this case study, effectively encompass the range of HCR modes observed in the warm season in central Oklahoma. Boundary layer organization (either rolls or cells), often develops in the late morning or early afternoon in a relatively shallow boundary layer. Through the day, as surface heating persists and the boundary layer deepens, cellular convection or HCRs may persist through the entire day or undergo transition to the other mode. HCR wavelengths often increase owing to the deepening of the boundary layer and simultaneous expansion of circulations (implying constant aspect ratio). HCRs that undergo transition to cellular convection in the afternoon also occasionally experience a second transition later in the day back to HCRs. As pure HCRs evolve or when HCRs form a second time late in the day, wavelengths often become larger, and sometimes significantly larger, than wavelengths observed earlier in the day. Finally, as sunset approaches and surface heating slows down, boundary layer circulation dissipates and the presence of HCRs or cellular convection on radar becomes indiscernible.

\section{Summary and future work}

Boundary layer organization is readily observed using WSR-88D radar data owing to the detection of insects lofted by boundary layer thermals. The widespread availability of radar data on clear air days lends itself well to investigating HCR and cell behaviors. We performed an analysis of 10 years of clear-air WSR-88D data over central Oklahoma and identified and characterized horizontal convective rolls and cellular convection during the warm season (April-September). Results indicate that HCRs or cellular convection, combined here as boundary layer organization, occur on $76 \%$ of the warm season days in Oklahoma. HCR wavelengths are 
typically between 2 and $10 \mathrm{~km}$, but can be as large as $30 \mathrm{~km}$, and $82 \%$ of HCRs exhibit increasing wavelength during their lifetime with an additional $15 \%$ maintaining constant wavelength. HCRs align, on average, approximately parallel to the mean boundary layer wind, but can align as much as $50^{\circ}$ to the right or left of the mean wind $\left(98 \%\right.$ within $30^{\circ}$ and $79 \%$ within $\left.10^{\circ}\right)$. Note that boundary layer winds are estimated using a fixed layer from 0.39 to $0.66 \mathrm{~km}$, which may be unrepresentative for some boundary layer wind profiles. That the majority of HCRs align within $10^{\circ}$ of the mean wind matches the findings in past studies (Table 1). This study, however, includes 462 cases, which far exceeds any previous work and bolsters confidence in these results.

HCRs are observed to persist as the only mode of boundary layer organization for a given day or undergo transition to or from cellular convection. Pure HCRs occur on 471 days during the 10 -yr climatology (26\% of all days, $34 \%$ of all days with boundary layer organization, and $44 \%$ of days with HCRs). The most common transition observed between modes of boundary layer organization occurs when HCRs develop prior to a transition to cellular convection. This occurs on 415 days over the 10 -yr climatology ( $23 \%$ of all days, $30 \%$ of days with boundary layer organization, and $39 \%$ of days with HCRs). A less common, though repeatable transition, involves the transition from cellular convection to HCRs late in the day (often within an hour or two of sunset). This transition occurs on 239 days, with 129 of those HCRs reforming after a transition to cellular convection earlier in the day. HCRs that form for the first time on a given day following a transition from cells account for $6 \%$ of all days, and $8 \%$ of days with boundary layer organization, and $10 \%$ of all days with HCRs. The environmental factors that influence HCR and cell evolution, including formation, transitions, and dissipation, are beyond the scope of this paper, but the results from this study provide a rich dataset with which possible mechanisms could be investigated.

The occurrence of HCRs with wavelengths greater than $10 \mathrm{~km}$ and up to $30 \mathrm{~km}$ late in the day represents a unique finding from this study. Such large wavelengths have been observed in previous studies, but only over water during the cold season (Table 1). These HCRs are representative of wide rolls observed over water during cold air outbreaks as described in Atkinson and Zhang (1996), but deserve further investigation. These wide rolls may be caused by interaction with gravity waves above the boundary layer as suggested by Clark et al. (1986), documented by LeMone and Meitin (1984) in the tropics during the warm season, and modeled by Balaji and Venkateshan (1993). Another possible explanation is proposed by Young et al. (2002), who note a major difference between narrow and wide rolls in the number of thermal updrafts responsible for sustaining the roll circulation. They suggest that narrow rolls are usually sustained by a single updraft with embedded smaller-scale turbulent fluctuations, whereas wide rolls are generally accompanied by multiple thermals within a given updraft that may combine as in Walter and Overland (1984). A modeling study using a large eddy simulation (LES) framework could prove useful at elucidating the dynamic and thermodynamic factors that influence the formation of these HCR-like features late in the day similar to the methodology of Salesky et al. (2017). Previous studies have used LES to simulate rolls, but model energetics and computational constraints have led to contrasting results (Glendening 1996; Weckwerth et al. 1997) as discussed by Atkinson and Zhang (1996). A high-resolution, large-domain, high-lid radiative boundary condition LES, as suggested by Young et al. (2002), could be used to investigate this overland wide roll phenomenon.

The combination of HCR and cell wavelength data and boundary layer depth estimates based on the method of Banghoff et al. (2018) from April through September in 2013-17 provide additional insights. Observed boundary layer depths range from about $500 \mathrm{~m}$ to $2 \mathrm{~km}$ and deepen during the day. HCR aspect ratios are most often between 1 and 8 with values of up to 22 observed, while cell aspect ratios are between 1 and 8 . Of particular note are the daytime and monthly trends of HCR aspect ratio with time. Previous studies of overland HCRs have found aspect ratio to be approximately constant (Young et al. 2002). The daytime behavior of aspect ratio found in this study (decrease, constant, then increase), however, indicates that other variables are likely important. Some of the larger values of aspect ratio in the morning may be caused by the influence of gravity waves above the convective boundary layer that could cause expansion of HCR updrafts as in Clark et al. (1986). Another possible explanation is the occurrence of HCRs in the residual layer, which would lead to a larger effective boundary layer depth and thus smaller aspect ratios. Residual layers are observable in quasivertical profiles of $Z_{\mathrm{DR}}$ and, although a cursory glance at a couple cases indicated rolls were not occurring the residual layer, further investigation may be worthwhile. Several plausible explanations exist, but further research is needed to understand what produces the previously undiscovered three-tiered daytime evolution and the monthly behavior of aspect ratio.

Now that typical HCR and cellular convection initiation and dissipation times, frequency, wavelength, and aspect ratio are quantified, these results can be used to compare against the occurrence of HCR- and cell-like 
signatures in high-resolution model output (Ching et al. 2014) or LES results. Similar climatologies could be developed in different locations across the country, especially if a more robust algorithm could be developed to automate identification of the presence of HCRs and cells on radar. In addition, incorporation of satellite observations into this dataset could provide useful insight on the effect of clouds on roll and cell evolution. The rapidly increasing amount and availability of meteorological observations is a treasure trove for gaining a better understanding of these important boundary layer features.

Acknowledgments. Funding for this work is provided by NSF Award AGS-1632850. Special thanks to members of the RADAR research group at Penn State University for sharing code and providing insightful suggestions. Additionally, the authors would like the thank Dr. Peggy LeMone and two anonymous reviewers who offered invaluable recommendations that improved the final version of the manuscript. This work is part of the first author's M.S. Thesis at Penn State University.

\section{REFERENCES}

Agee, E. M., and K. Dowell, 1974: Observational studies of mesoscale cellular convection. J. Appl. Meteor., 13, 46-53, https://doi.org/ 10.1175/1520-0450(1974)013<0046:OSOMCC >2.0.CO;2.

—, T. Chen, and K. Dowell, 1973: A review of mesoscale cellular convection. Bull. Amer. Meteor. Soc., 54, 1004-1012, https:// doi.org/10.1175/1520-0477(1973)054<1004:AROMCC >2.0.CO;2.

American Meteorological Society, 2019: Horizontal convective rolls. Glossary of Meteorology, http://glossary.ametsoc.org/ wiki/Horizontal_convective_rolls.

Angell, J. K., D. H. Pack, and C. Dickson, 1968: A Lagrangian study of helical circulations in the planetary boundary layer. J. Atmos. Sci., 25, 707-717, https://doi.org/10.1175/ 1520-0469(1968)025<0707:ALSOHC>2.0.CO;2.

Asai, T., 1972: Thermal instability of a shear flow turning the direction with height. J. Meteor. Soc. Japan, 50, 525-532, https:// doi.org/10.2151/JMSJ1965.50.6_525.

Atkinson, B., and J. Zhang, 1996: Mesoscale shallow convection in the atmosphere. Rev. Geophys., 34, 403-431, https://doi.org/ 10.1029/96RG02623.

Atlas, D., S.-H. Chou, and W. P. Byerly, 1983: The influence of coastal shape on winter mesoscale air-sea interaction. Mon. Wea. Rev., 111, 245-252, https://doi.org/10.1175/15200493(1983) $111<0245$ :TIOCSO > 2.0.CO;2.

— B. Walter, S.-H. Chou, and P. Sheu, 1986: The structure of the unstable marine boundary layer viewed by lidar and aircraft observations. J. Atmos. Sci., 43, 1301-1318, https://doi.org/ 10.1175/1520-0469(1986)043<1301:TSOTUM>2.0.CO;2.

Bakan, S., and E. Schwarz, 1992: Cellular convection over the north-eastern Atlantic. Int. J. Climatol., 12, 353-367, https:// doi.org/10.1002/joc.3370120404.

Balaji, C., and S. Venkateshan, 1993: Interaction of surface radiation with free convection in a square cavity. Int. J. Heat Fluid Flow, 14, 260-267, https://doi.org/10.1016/0142-727X(93)90057-T.
Banghoff, J. R., D. J. Stensrud, and M. R. Kumjian, 2018: Convective boundary layer depth estimation from S-band dualpolarization radar. J. Atmos. Oceanic Technol., 35, 1723-1733, https://doi.org/10.1175/JTECH-D-17-0210.1.

Bennett, L. J., T. M. Weckwerth, A. M. Blyth, B. Geerts, Q. Miao, and Y. P. Richardson, 2010: Observations of the evolution of the nocturnal and convective boundary layers and the structure of open-celled convection on 14 June 2002. Mon. Wea Rev., 138, 2589-2607, https://doi.org/10.1175/2010MWR3200.1.

Berger, M., and R. Doviak, 1978: Dual Doppler radar observations of wind fields in a dry convective boundary layer. Symp. on Meteorological Observations and Instrumentation, Denver, CO, Amer. Meteor. Soc., 219-226.

Bloomfield, P., 2004: Fourier Analysis of Time Series: An Introduction. John Wiley \& Sons, $288 \mathrm{pp}$.

Braham, R., 1986: Cloud and motion fields in open cell convection over Lake Michigan. Preprints, 23rd Conf. on Radar Meteorology/Conf. on Cloud Physics, Snowmass, CO, Amer. Meteor. Soc., JP202-JP205.

Brown, R. A., 1980: Longitudinal instabilities and secondary flows in the planetary boundary layer: A review. Rev. Geophys., $\mathbf{1 8}$ 683-697, https://doi.org/10.1029/RG018i003p00683.

Browning, K., and R. Wexler, 1968: The determination of kinematic properties of a wind field using Doppler radar. J. Appl. Meteor., 7, 105-113, https://doi.org/10.1175/1520-0450(1968) 007<0105:TDOKPO $>2.0 . \mathrm{CO} ; 2$.

Brümmer, B., 1999: Roll and cell convection in wintertime arctic cold-air outbreaks. J. Atmos. Sci., 56, 2613-2636, https://doi.org/ 10.1175/1520-0469(1999)056<2613:RACCIW >2.0.CO;2.

Chang, H.-R., and H. N. Shirer, 1984: Transitions in shallow convection: An explanation for lateral cell expansion. J. Atmos. Sci., 41, 2334-2346, https://doi.org/10.1175/1520-0469(1984) 041<2334:TISCAE $>2.0$. CO;2.

Chapman, J. W., V. A. Drake, and D. R. Reynolds, 2011: Recent insights from radar studies of insect flight. Annu. Rev. Entomol., 56, 337-356, https://doi.org/10.1146/annurev-ento-120709-144820.

Ching, J., R. Rotunno, M. LeMone, A. Martilli, B. Kosovic, P. Jimenez, and J. Dudhia, 2014: Convectively induced secondary circulations in fine-grid mesoscale numerical weather prediction models. Mon. Wea. Rev., 142, 3284-3302, https:// doi.org/10.1175/MWR-D-13-00318.1.

Chlond, A., 1992: Three-dimensional simulation of cloud street development during a cold air outbreak. Bound.-Layer Meteor., 58, 161-200, https://doi.org/10.1007/BF00120757.

Christian, T. W., and R. M. Wakimoto, 1989: The relationship between radar reflectivities and clouds associated with horizontal roll convection on 8 August 1982. Mon. Wea. Rev., 117, 1530-1544, https://doi.org/10.1175/1520-0493(1989)117<1530: TRBRRA $>2.0 . \mathrm{CO} ; 2$.

Clark, T. L., T. Hauf, and J. P. Kuettner, 1986: Convectively forced internal gravity waves: Results from two-dimensional numerical experiments. Quart. J. Roy. Meteor. Soc., 112, 899-925, https:// doi.org/10.1002/qj.49711247402.

Deardorff, J. W., 1972: Parameterization of the planetary boundary layer for use in general circulation models. Mon. Wea Rev., 100, 93-106, https://doi.org/10.1175/1520-0493(1972) $100<0093:$ POTPBL $>2.3 . \mathrm{CO} ; 2$.

Drake, V., and R. Farrow, 1988: The influence of atmospheric structure and motions on insect migration. Annu. Rev. Entomol., 33, 183-210, https://doi.org/10.1146/annurev.en.33.010188.001151.

Etling, D., and R. Brown, 1993: Roll vortices in the planetary boundary layer: A review. Bound.-Layer Meteor., 65, 215-248, https://doi.org/10.1007/BF00705527. 
Fankhauser, J., N. Crook, J. Tuttle, L. Miller, and C. Wade, 1995: Initiation of deep convection along boundary layer convergence lines in a semitropical environment. Mon. Wea. Rev., 123, 291-314, https://doi.org/10.1175/1520-0493(1995)123<0291: IODCAB $>2.0 . \mathrm{CO} ; 2$.

Geerts, B., and Q. Miao, 2005: Airborne radar observations of the flight behavior of small insects in the atmospheric convective boundary layer. Environ. Entomol., 34, 361-377, https:// doi.org/10.1603/0046-225X-34.2.361.

Glendening, J. W., 1996: Lineal eddy features under strong shear conditions. J. Atmos. Sci., 53, 3430-3449, https://doi.org/ 10.1175/1520-0469(1996)053<3430:LEFUSS > 2.0.CO;2.

Hardy, K. R., and H. Ottersten, 1969: Radar investigations of convective patterns in the clear atmosphere. J. Atmos. Sci., 26, 666-672, https://doi.org/10.1175/1520-0469(1969)26<666: $\mathrm{RIOCPI}>2.0 . \mathrm{CO} ; 2$.

Helfand, H. M., and E. Kalnay, 1983: A model to determine open or closed cellular convection. J. Atmos. Sci., 40, 631-650, https:// doi.org/10.1175/1520-0469(1983)040<0631:AMTDOO>2.0.CO;2.

Hildebrand, P., 1980: Multiple Doppler radar observations of PBL structure. 19th Conf. on Radar Meteorology, Miami, FL, Amer. Meteor. Soc., 656-661.

Kelly, R. D., 1982: A single Doppler radar study of horizontal-roll convection in a lake-effect snow storm. J. Atmos. Sci., 39, 1521-1531, https://doi.org/10.1175/1520-0469(1982)039<1521: ASDRSO $>2.0 . \mathrm{CO} ; 2$.

_ , 1984: Horizontal roll and boundary-layer interrelationships observed over Lake Michigan. J. Atmos. Sci., 41 1816-1826, https://doi.org/10.1175/1520-0469(1984)041<1816: HRABLI $>2.0 . \mathrm{CO} ; 2$.

Konrad, T. G., 1970: The dynamics of the convective process in clear air as seen by radar. J. Atmos. Sci., 27, 1138-1147, https://doi.org/ 10.1175/1520-0469(1970)027<1138:TDOTCP >2.0.CO;2.

Kristovich, D. A., N. F. Laird, M. R. Hjelmfelt, R. G. Derickson, and K. A. Cooper, 1999: Transitions in boundary layer meso$\gamma$ convective structures: An observational case study. Mon. Wea. Rev., 127, 2895-2909, https://doi.org/10.1175/ 1520-0493(1999)127<2895:TIBLMC >2.0.CO;2.

Kropfli, R. A., and N. M. Kohn, 1978: Persistent horizontal rolls in the urban mixed layer as revealed by dual-Doppler radar. J. Appl. Meteor., 17, 669-676, https://doi.org/10.1175/15200450(1978)017<0669:PHRITU > 2.0.CO;2.

Kuettner, J., 1959: The band structure of the atmosphere. Tellus, 11, 267-294, https://doi.org/10.3402/tellusa.v11i3.9319.

Kuettner, J. P., 1971: Cloud bands in the Earth's atmosphere: Observations and theory. Tellus, 23, 404-426, https://doi.org/ 10.3402/tellusa.v23i4-5.10519.

Laufersweiler, M. J., and H. N. Shirer, 1989: A simple dynamical model of a stratocumulus-topped boundary layer. J. Atmos. Sci., 46, 1133-1153, https://doi.org/10.1175/1520-0469(1989) 046<1133:ASDMOA > 2.0.CO;2.

LeMone, M. A., 1973: The structure and dynamics of horizontal roll vortices in the planetary boundary layer. J. Atmos. Sci., 30, 1077-1091, https://doi.org/10.1175/1520-0469(1973)030<1077: TSADOH $>2.0 . \mathrm{CO} ; 2$.

_ - and W. T. Pennell, 1976: The relationship of trade wind cumulus distribution to subcloud layer fluxes and structure. Mon. Wea. Rev., 104, 524-539, https://doi.org/10.1175/15200493(1976) $104<0524$ :TROTWC $>2.0$.CO;2.

_ and R. J. Meitin, 1984: Three examples of fair-weather mesoscale boundary-layer convection in the tropics. Mon. Wea. Rev., 112, 1985-1998, https://doi.org/10.1175/1520-0493(1984) $112<1985$ :TEOFWM $>2.0$. CO 2 .
—, F. Chen, M. Tewari, J. Dudhia, B. Geerts, Q. Miao, R. L. Coulter, and R. L. Grossman, 2010: Simulating the IHOP_2002 fairweather CBL with the WRF-ARW-Noah modeling system. Part II: Structures from a few kilometers to $100 \mathrm{~km}$ across. Mon. Wea. Rev., 138, 745-764, https://doi.org/10.1175/2009MWR3004.1.

Melfi, S., and S. P. Palm, 2012: Estimating the orientation and spacing of midlatitude linear convective boundary layer features: Cloud streets. J. Atmos. Sci., 69, 352-364, https://doi.org/ 10.1175/JAS-D-11-070.1.

Miles, N. L., and J. Verlinde, 2005a: Observations of transient linear organization and nonlinear scale interactions in lakeeffect clouds. Part I: Transient linear organization. Mon. Wea. Rev., 133, 677-691, https://doi.org/10.1175/MWR-2879.1.

$\longrightarrow$, and — 2005b: Observations of transient linear organization and nonlinear scale interactions in lake-effect clouds. Part II: Nonlinear scale interactions. Mon. Wea. Rev., 133, 692-706, https://doi.org/10.1175/MWR-2880.1.

Miura, Y., 1986: Aspect ratios of longitudinal rolls and convection cells observed during cold air outbreaks. J. Atmos. Sci., 43, 26-39, https://doi.org/10.1175/1520-0469(1986)043<0026: AROLRA $>2.0 . \mathrm{CO} ; 2$.

Plank, V. G., 1966: Wind conditions in situations of patternform and non-patternform cumulus convection. Tellus, 18, 1-12, https://doi.org/10.3402/tellusa.v18i1.9193.

Reinking, R., R. Doviak, and R. Gilmer, 1981: Clear-air roll vortices and turbulent motions as detected with an airborne gust probe and dual-Doppler radar. J. Appl. Meteor., 20, 678-685, https://doi.org/10.1175/1520-0450(1981)020<0678: CARVAT $>2.0 . \mathrm{CO} ; 2$

Rothermel, J., and E. M. Agee, 1980: Aircraft investigation of mesoscale cellular convection during AMTEX 75. J. Atmos. Sci., 37, 1027-1040, https://doi.org/10.1175/1520-0469(1980) 037<1027:AIOMCC >2.0.CO;2.

Russell, R. W., and J. W. Wilson, 1997: Radar-observed "fine lines" in the optically clear boundary layer: reflectivity contributions from aerial plankton and its predators. Bound.-Layer Meteor., 82, 235-262, https://doi.org/10.1023/A:1000237431851.

Salesky, S. T., M. Chamecki, and E. Bou-Zeid, 2017: On the nature of the transition between roll and cellular organization in the convective boundary layer. Bound.-Layer Meteor., 163, 41-68, https://doi.org/10.1007/s10546-016-0220-3.

Schuetz, J., and S. Fritz, 1961: Cloud streets over the Caribbean Sea. Mon. Wea. Rev., 89, 375-382, https://doi.org/10.1175/ 1520-0493(1961)089<0375:CSOTCS > 2.0.CO;2.

Sheu, P.-J., E. M. Agee, and J. J. Tribbia, 1980: A numerical study of physical processes affecting convective cellular geometry. J. Meteor. Soc. Japan, 58, 489-499, https://doi.org/10.2151/ JMSJ1965.58.6_489.

Stull, R. B., 1988: An Introduction to Boundary Layer Meteorology. Kluwer Academic, $666 \mathrm{pp}$.

Sykes, R., W. Lewellen, and D. Henn, 1988: A numerical study of the development of cloud-street spacing. J. Atmos. Sci., 45, 2556-2570, https://doi.org/10.1175/1520-0469(1988)045<2556: ANSOTD $>2.0 . \mathrm{CO} ; 2$.

U. S. Department of Agriculture National Water and Climate Center, 2019: Oklahoma City/Will Rogers World Airport, OK wind rose plot. Accessed 4 March 2019, https://www.wcc.nrcs.usda.gov/ ftpref/downloads/climate/windrose/oklahoma/oklahoma_city/.

Vaughn, C. R., 1985: Birds and insects as radar targets: A review. Proc. IEEE, 73, 205-227, https://doi.org/10.1109/PROC.1985.13134.

Wakimoto, R. M., and J. W. Wilson, 1989: Non-supercell tornadoes. Mon. Wea. Rev., 117, 1113-1140, https://doi.org/10.1175/ 1520-0493(1989)117<1113:NST>2.0.CO;2. 
Walter, B., and J. Overland, 1984: Observations of longitudinal rolls in a near neutral atmosphere. Mon. Wea. Rev., 112, 200-208, https://doi.org/10.1175/1520-0493(1984)112<0200: OOLRIA $>2.0 . \mathrm{CO} ; 2$.

Weckwerth, T. M., J. W. Wilson, R. M. Wakimoto, and N. A. Crook, 1997: Horizontal convective rolls: Determining the environmental conditions supporting their existence and characteristics. Mon. Wea. Rev., 125, 505-526, https://doi.org/ 10.1175/1520-0493(1997)125<0505:HCRDTE > 2.0.CO;2.

- T. W. Horst, and J. W. Wilson, 1999: An observational study of the evolution of horizontal convective rolls. Mon. Wea. Rev., 127, 2160-2179, https://doi.org/10.1175/1520-0493(1999) 127<2160:AOSOTE $>2.0$. CO;2.

, H. V. Murphey, C. Flamant, J. Goldstein, and C. R. Pettet, 2008: An observational study of convection initiation on 12 June 2002 during IHOP_2002. Mon. Wea. Rev., 136, 22832304, https://doi.org/10.1175/2007MWR2128.1.

Weston, K., 1980: An observational study of convective cloud streets. Tellus, 32, 433-438, https://doi.org/10.3402/ tellusa.v32i5.10598.
Wilson, J. W., G. B. Foote, N. A. Crook, J. C. Fankhauser, C. G. Wade, J. D. Tuttle, C. K. Mueller, and S. K. Krueger, 1992: The role of boundary-layer convergence zones and horizontal rolls in the initiation of thunderstorms: A case study. Mon. Wea. Rev., 120, 1785-1815, https://doi.org/10.1175/15200493(1992)120<1785:TROBLC > 2.0.CO;2.

_ , T. M. Weckwerth, J. Vivekanandan, R. M. Wakimoto, and R. W. Russell, 1994: Boundary layer clear-air radar echoes: Origin of echoes and accuracy of derived winds. J. Atmos. Oceanic Technol., 11, 1184-1206, https://doi.org/10.1175/15200426(1994)011<1184:BLCARE > 2.0.CO;2.

Woodcock, A. H., 1942: Soaring over the open sea. Sci. Mon., 55, 226-232.

Yang, Q., and B. Geerts, 2006: Horizontal convective rolls in cold air over water: Buoyancy characteristics of coherent plumes detected by an airborne radar. Mon. Wea. Rev., 134, 2373 2396, https://doi.org/10.1175/MWR3203.1.

Young, G. S., D. A. Kristovich, M. R. Hjelmfelt, and R. C. Foster, 2002: Supplement to rolls, streets, waves, and more. Bull. Amer. Meteor. Soc., 83, 1001-1001, https://doi.org/10.1175/BAMS-83-7-Young. 